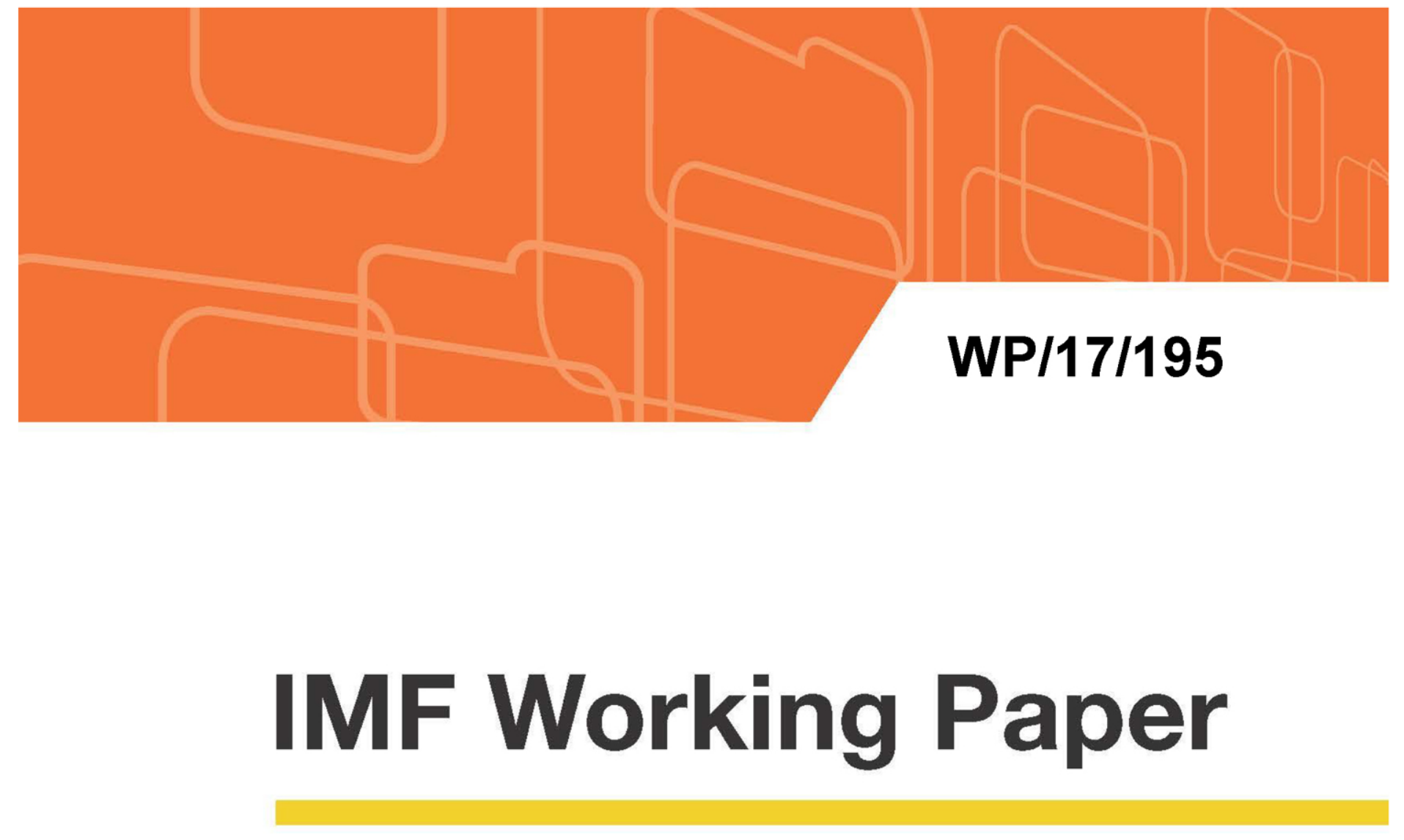

\title{
The Political Economy of Fiscal Transparency and Independent Fiscal Councils
}

by Roel M.W.J. Beetsma, Xavier Debrun and Randolph Sloof

IMF Working Papers describe research in progress by the author(s) and are published to elicit comments and to encourage debate. The views expressed in IMF Working Papers are those of the author(s) and do not necessarily represent the views of the IMF, its Executive Board, or IMF management. 


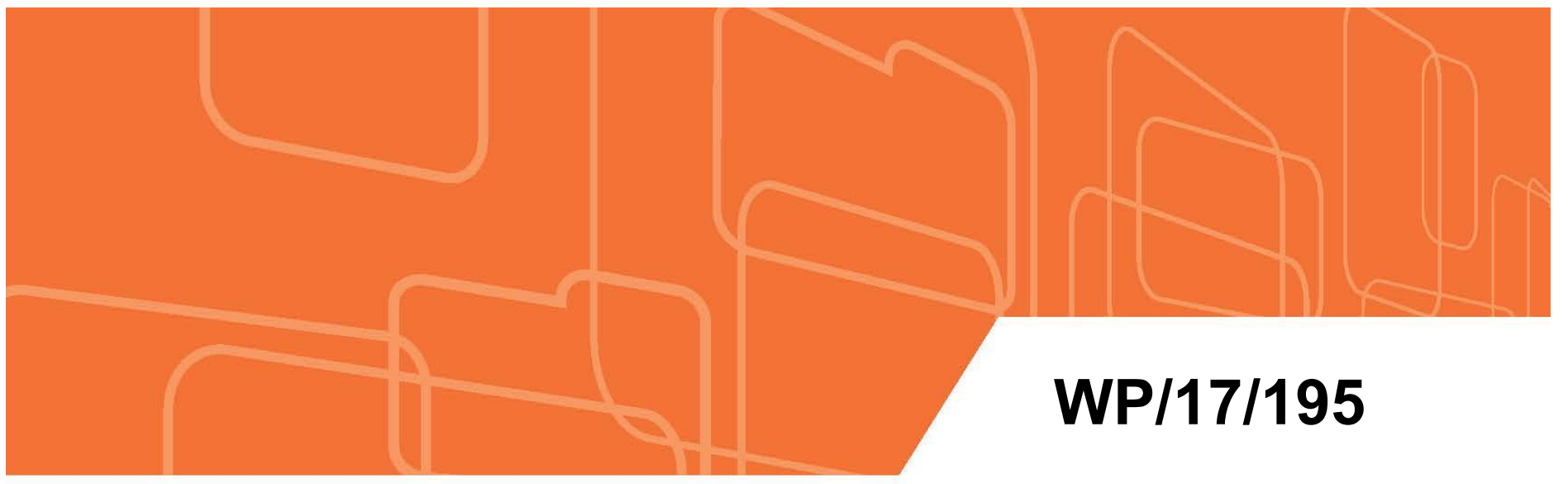

\section{IMF Working Paper}

\section{The Political Economy of Fiscal Transparency and Independent Fiscal Councils}

by Roel M.W.J. Beetsma, Xavier Debrun and Randolph Sloof

IMF Working Papers describe research in progress by the author(s) and are published to elicit comments and to encourage debate. The views expressed in IMF Working Papers are those of the author(s) and do not necessarily represent the views of the IMF, its Executive Board, or IMF management.

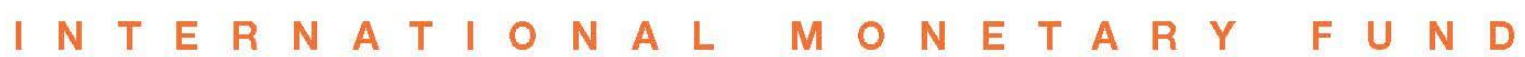




\title{
IMF Working Paper
}

\author{
Research Department
}

\section{The Political Economy of Fiscal Transparency and Independent Fiscal Councils* Prepared by Roel Beetsma ${ }^{\phi}$, Xavier Debrun\% and Randolph Sloof ${ }^{\&}$}

\author{
Authorized for distribution by Jonathan D. Ostry
}

September 2017

\begin{abstract}
This Working Paper should not be reported as representing the views of the IMF. The views expressed in this Working Paper are those of the author(s) and do not necessarily represent those of the IMF or IMF policy. Working Papers describe research in progress by the author(s) and are published to elicit comments and to further debate.
\end{abstract}

\begin{abstract}
The global surge in independent fiscal councils (IFCs) raises three related questions: How can IFCs improve the conduct of fiscal policy? Are they simultaneously desirable for voters and elected policymakers? And are they resilient to changes in political conditions? We build a model in which voters cannot observe the true competence of elected policymakers. IFCs' role is to mitigate this imperfection. Equilibrium public debt is excessive because policymakers are "partisan" and "opportunistic." If voters only care about policymakers' competence, both the incumbent and the voters would be better off with an IFC as the debt bias would shrink. However, when other considerations eclipse competence and give the incumbent a strong electoral advantage or disadvantage, setting up an IFC may be counterproductive as the debt bias would increase. If the incumbent holds a moderate electoral advantage or disadvantage, voters would prefer an IFC, but an incumbent with a large advantage may prefer not to have an IFC. The main policy implications are that (i) establishing an IFC can only lower the debt bias if voters care sufficiently about policymakers' competence; (ii) not all political environments are conducive to the emergence of IFCs; and (iii) IFCs are consequently vulnerable to shifts in political conditions.
\end{abstract}

JEL Classification Numbers: E62; H6

Keywords: Independent fiscal councils, Fiscal transparency, public debt, partisan bias, opportunistic bias, competence, congruence.

Authors Email Addresses: r.m.w.j.beetsma@uva.nl; xdebrun@imf.org; r.sloof@uva.nl

\footnotetext{
* Part of this paper was prepared by Beetsma under the Wim Duisenberg Research Fellowship Program sponsored by the ECB. We are grateful to Xiaoxiao Zhang for excellent research assistance. We thank participants at the SEEK-ENBI Workshop on Fiscal Governance in the Eurozone: The Role of Rules, Fiscal Boards and Other Policy Innovations (Mannheim, November 24-25, 2016) and, in particular, our discussant Michal Horvath. We also thank participants at the ADEMU Conference "How much of a Fiscal Union for the EMU?" (Banco d'España, May 18-19, 2017) and, in particular, our discussant, Carlos Mulas-Granados.

$\phi$ MN Chair in Pension Economics, University of Amsterdam; European Fiscal Board; CEPR; CESifo; Netspar; Tinbergen Institute. Address: Amsterdam School of Economics, University of Amsterdam, P.O. Box 15867, 1001 NJ Amsterdam, The Netherlands; phone: +31.20.5255280; e-mail: r.m.w.j.beetsma@uva.nl.

$\%$ Research Department, International Monetary Fund 700, 19th St. NW Washington DC 20431; phone: +1.202.6400827; email: xdebrun@imf.org.

\& University of Amsterdam; Tinbergen Institute. Address: Amsterdam School of Economics, University of Amsterdam, P.O. Box 15867, 1001 NJ Amsterdam, The Netherlands; phone: +31.20.5255241; r.sloof@uva.nl.
} 


\section{Contents}

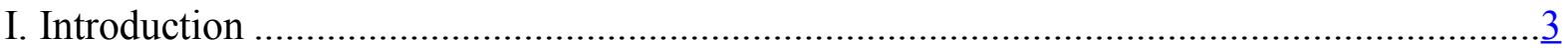

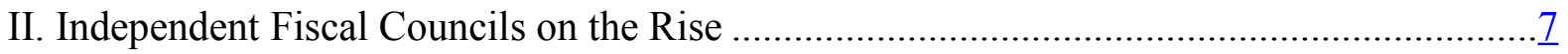

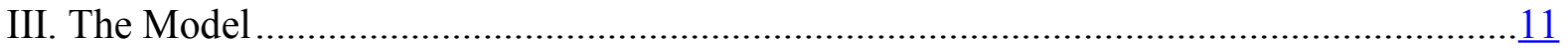

IV. First-Best Benchmark: The Social Planner Solution ..................................................14

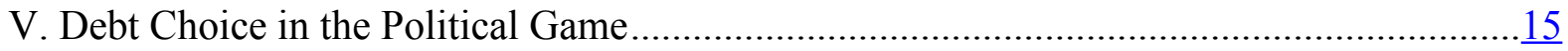

A. Belief Formation and Updating............................................................. $\frac{15}{17}$

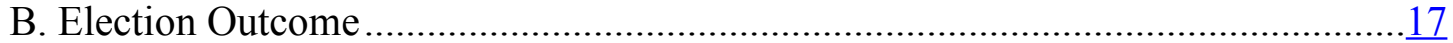

C. Equilibrium Public Debt..................................................................................

VI. More Transparency? The Effect of a Fiscal Council on Equilibrium Debt......................20

VII. Who Wants a Fiscal Council? The Incumbent's Case ..............................................24

VIII. Who Wants a Fiscal Council? The Voters' Case.....................................................26

IX. Other Manifestations of Fiscal Transparency........................................................29

X. Politics and the Emergence of IFCs: Are Stylized Facts Consistent with Theory? .............33

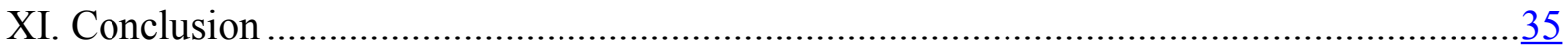

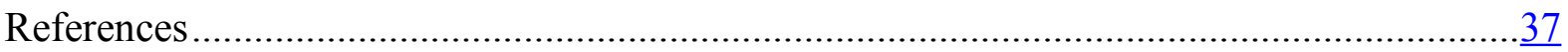

Table

1: Panel Averages of Variables Capturing Polarization Elements...................................... $\underline{34}$

Figures

1. Number of Independent Fiscal Councils in the World .................................................. $\frac{8}{9}$

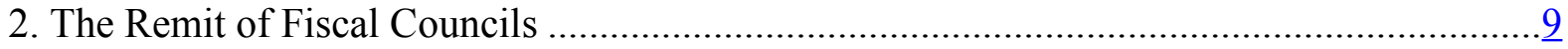

3. Channels of Influence on the Budget Process.................................................................

4. Guarantees of Independence ............................................................................ 10

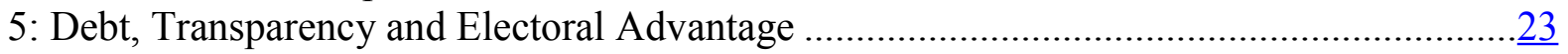

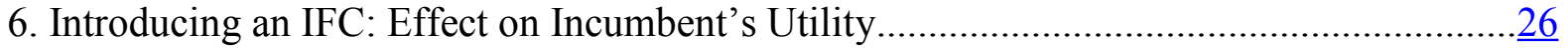

7. Introducing an IFC: Effects on Social Welfare vs. Incumbent's Utility............................28

Appendix

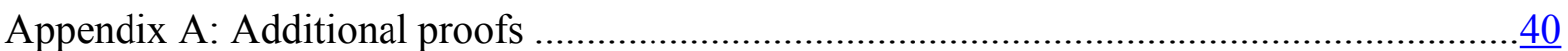


"A popular government without popular information or the means of acquiring it, is but a prologue to a farce, or a tragedy, or perhaps both."

James Madison (1822)

\section{INTRODUCTION}

Over the past decade, the number of countries with independent fiscal councils (IFCs) has more than tripled, to almost 40. Although IFCs do not control any fiscal policy instrument, their official role as public finance watchdogs is expected to improve the quality of the public debate on fiscal policy, thereby encouraging better fiscal outcomes (Debrun et al. 2013; Kopits, 2013). However, because fiscal policy is inherently political, ${ }^{1}$ it is natural to wonder how a group of unelected experts could meaningfully strengthen elected policymakers' incentives to run better policies. In one way or another, IFCs' effectiveness must entail some degree of constraint on policymakers' discretion. It is therefore critical to understand what motivates elected officials to establish effective IFCs in the first place.

To be sure, not all political environments and economic circumstances can be expected to favor the adoption of such institutions and their continued influence on the conduct of fiscal policy. However, there is no theory coming close to elucidate the fundamental drivers of their birth, their effectiveness, and the existential threats they may occasionally face. Our aim is to fill this gap with a political-economy model shedding light on three main questions: How can IFCs improve the conduct of fiscal policy? Are they simultaneously desirable for voters and elected policymakers? And are they resilient to changes in political conditions? Ultimately, we try to rigorously qualify the emerging view that IFCs may be the new universal panacea to poor fiscal performance and broken fiscal rules.

Our model features two political parties - an incumbent and a challenger-competing for office. Voters assess political parties along two dimensions: "competence" and "congruence." Our metric for "competence" is the quantity of public goods and services a party can provide out of a given resource pool. As such, it captures a party's ability to run the public sector in an efficient manner. It is assumed to be stochastic and not directly observed by the voting public. "Congruence" refers to any other determinant of voters' preference in favor of a given political party. It includes ideological alignment, the sense of empathy coming from party leadership, etc. For instance, if voters care about the global warming impact of carbon emissions and must choose between two equally competent political parties, they would prefer the party that will spend a billion euros on a new commuter train line rather than on a new highway. Together, congruence and competence shape electoral outcomes and popularity.

In line with a long tradition in the literature, the model exhibits a bias towards excessive public deficits and debts. The equilibrium debt level deviates from its socially-optimal value

\footnotetext{
${ }^{1}$ Jefferson's principle of "No taxation without representation" is the best-known reflection of this.
} 
for two reasons. The first one is policymakers' myopia characterizing the "partisan" deficit bias studied in Alesina and Tabellini (1990). Because it will no longer benefit from the right to spend public resources if it is voted out of office, the incumbent party finds it optimal to spend more now and pass the problem of repaying the debt to its successor. The second source of deficit bias is "opportunism" in the tradition of Rogoff and Sibert (1988). To improve re-election chances, the incumbent opportunistically spends more than a hypothetical social planner just to appear more competent to voters. In equilibrium, the attempt to raise re-election chances in this way is futile and debt is too high.

As far as we know, this paper is the first to combine these two sources of deficit bias in relation to fiscal transparency. ${ }^{2}$ The "opportunistic" debt bias would vanish if society had complete information about the incumbent's competence. Thus, increasing fiscal transparency may alleviate the deficit bias. This is where IFCs come into play as their task is precisely to provide an objective analysis of fiscal policy that can help voters debunk the "fiscal alchemy"3 emanating from official budget documents and other partisan sources of information. An effective IFC thus provides the public with clearer information about policymakers' competence, allowing voters to make better-informed decisions.

We find that, if voters rank political party based only on perceived competence, effective IFCs raise both social welfare and the incumbent's utility. The greater precision with which the incumbent's competence can be inferred will defeat the purpose of engaging in costly, but in equilibrium futile, expenditure increases to appear more competent.

The analysis is subtler when voters are simultaneously interested in competence and congruence. For given competence, congruence makes policymakers popular, giving them an electoral advantage. Considering the partisan deficit bias in isolation, introducing an IFC lowers re-election chances of a popular incumbent because it increases the risk of being exposed as less competent and consequently erodes his advantage in the electoral contest. Reduced re-election chances in turn cause equilibrium debt to rise. Considering the opportunistic debt bias in isolation, an IFC contributes to lower equilibrium debt if the electoral advantage is limited or non-existent, but it leads to higher debt if the electoral advantage is large enough. The overall effect of an IFC on equilibrium public debt thus depends on the combination of the individual effects through the two sources of deficit biTas. For an electoral advantage in a certain interval, introducing an IFC lowers equilibrium debt, but it can raise debt otherwise.

\footnotetext{
${ }^{2}$ Fiscal transparency is interpreted in the broad sense of a better ability for the public to understand the true motivations behind policy actions and to assess the chances of meeting policy objectives with such actions. It follows from the IMF (http://www.imf.org/external/np/fad/trans/index.htm) definition of fiscal transparency as "The comprehensiveness, clarity, reliability, timeliness, and relevance of public reporting on the past, present, and future state of public finances." Transparency aims at providing an "accurate picture of [govvernment] finances," which includes cost-benefit analyses of policy changes, risks to public finances and comprehensive public sector balance sheets.

${ }^{3}$ To borrow Leeper's (2011) famous characterization of the conduct of fiscal policy.
} 
Turning to social welfare, voters' support for an IFC not only depends on its effect on debt (inter-temporal resource allocation) but also on the average competence of the incumbent (if re-elected). A key positive consequence of introducing an IFC is that more precise information about competence implies that re-elected incumbents are on average more competent than in the absence of an IFC. When assessing its own re-election chances, the incumbent also considers the effect of an IFC. If voters only care about competence, an IFC raises not only social welfare but also the incumbent's utility because the "opportunistic" motive for issuing debt is suppressed. When congruence matters (and a popular advantage or disadvantage exists), a moderately unpopular incumbent would still benefit from an IFC, while, for fear of being exposed as incompetent, a popular one might prefer not to have an effective IFC in place - at least if its benefit from holding office is large enough. When the incumbent is highly popular or unpopular, voters may also lose out from having an IFC in place because the welfare loss from higher debt could exceed the benefit of better selection. Clearly, social and incumbent's preferences regarding the establishment of an IFC may differ. In particular, when the incumbent is moderately popular, it may, in contrast to society, not want to install an IFC.

We further enrich the model by considering additional channels through which an IFC can enhance transparency. If debt itself is not perfectly observable, then an increase in the chance that it is precisely observed lowers equilibrium debt, boosting both the incumbent's utility and social welfare. Improving the chances of precisely observing the debt could be achieved by mandating the IFC to monitor public debt sustainability, a choice made by a majority of countries with IFCs (see Section II). An increase in the chance that competence is observed with perfect precision yields results qualitatively similar to those associated with a lower noise variance in the competence signal to the voters. In particular, if the incumbent is unpopular, an increase in the chance that competence is observed with perfect precision lowers debt, and raises the incumbent's utility and social welfare.

Our analysis has both positive and nominative implications. On the positive side, it helps explain why some countries adopt an IFC and others not, or why some IFCs suffer from design flaws (e.g. limited access to information) and resource constraints that impair their effectiveness. It can also capture episodes of tensions between governments and IFCs when political conditions change-for instance when congruence eclipses competence as the driver of voting behavior. In line with our analysis of voters' and incumbents' incentives, political data suggest that countries without IFCs tend to exhibit a stronger position of the executive. In the same vein, the well-documented "incumbency advantage" may partly explain why IFCs have been slow to emerge and why they are sometimes poorly designed and only weakly protected against political interference. Finally, the possibility of strongly diverging interests between the incumbent and the voters might explain why some presidential regimes like the United States or Korea have seen IFCs emanate directly from the legislative branch's desire to reassert better control over the public purse through greater transparency. 
On the normative side, the analysis suggests that the introduction of an IFC should go hand in hand with formal fiscal restraints to prevent the potential adverse effect of greater transparency on public debt in certain political conditions. This echoes the approach in many countries with fiscal policy rules and where IFCs received the explicit mandate to monitor adherence to these rules.

This paper relates to a rich literature on the politics of fiscal policy. One strand of that literature explains macroeconomic outcomes in the context of a game-theoretic setting. Early contributions include Rogoff and Sibert (1988) and Rogoff (1990), who model "political business cycles" in fiscal and macroeconomic variables as the result of signaling by incumbent governments in the presence of information asymmetries. In the context of a twoperiod model with elections and unknown incumbent competence, Bonfiglioli and Gancia (2013) show that the incumbent has an incentive to signal ability by underinvesting in costly policies with future pay-offs. They find that more uncertainty about competence may reduce myopia and improve social welfare.

Another relevant strand of the literature explores the theoretical or empirical consequences of increasing fiscal transparency. Alt et al. (2006) find that both political factors and fiscal policy outcomes affect fiscal transparency at the level of U.S. states. In the context of a career-concerns model with political parties, Alt and Lassen (2006) explore how fiscal transparency affects debt accumulation, which is used strategically by the incumbent to appear more competent. They construct a transparency index for 19 OECD countries and find a negative association between public debt and transparency. Gavazza and Lizzeri (2011) show that enhanced transparency may lead to more wasteful transfers in a framework in which transfers are set by the government to affect its re-election probability. There are key differences between these papers and ours. First, we focus on (a comparison of) the circumstances under which an elected policymaker and voters would prefer to establish an IFC. While more transparency raises welfare in Alt and Lassen (2006), adopting an IFC does not necessarily do so in our context. Second, congruence plays no role in Gavazza and Lizzeri (2011), while it is a key driving force of our results. Third, unlike this paper, Gavazza and Lizzeri (2011) do not explicitly analyze optimal public debt, while Alt and Lassen's (2006) model features only the opportunistic debt bias. They find that more transparency has an unambiguously negative effect on the equilibrium debt, while our framework yields ambiguous effects conditioned on the role of congruence in voting behavior. ${ }^{4}$

The present paper also relates to the literature describing the emergence of IFCs and their design features. Larch (2016) studies the delegation of fiscal stabilization to IFCs, while Horvath (2016) investigates how IFCs can be designed to effectively scrutinize national fiscal policies. Formal empirical work on the effectiveness of IFCs is rare, reflecting limited

\footnotetext{
${ }^{4}$ Gavazza and Lizzeri (2009) analyze the effects of transparency in government expenditures and revenues in a model with purely office-motivated politicians and find that debt is decreasing in transparency of expenditures.
} 
experience in most countries. Debrun et al. $(2009,2013)$ find positive associations between fiscal performance and the presence of an IFC, in part because they appear to encourage the adoption of stricter fiscal rules. Calmfors and Wren-Lewis (2011) study the recent experience with IFCs and argue that they should only have an advisory role and complement fiscal rules. Also related and relevant is the literature on fiscal rules, whose adoption tends to precede the emergence of IFCs (Beetsma and Debrun, 2017). Examples of theoretical analyses include Beetsma and Uhlig (1999), and Beetsma and Debrun (2007). On the empirical side, Bergman and Hutchison (2015) show empirically that fiscal rules are only effective in reducing the pro-cyclicality of fiscal policy when government efficiency is sufficiently high. MilesiFerretti (2003) proposes a theory of fiscal rule compliance in the presence of imperfect budgetary transparency, while Alt et al. (2014) analyze empirically the use of creative accounting to formally comply with EU fiscal rules.

The remainder of this paper is structured as follows. Section II documents the recent surge in independent fiscal councils as well as their main features. Section III lays out the basic elements of our model. Equilibrium debt levels are first derived in the social planner conjecture (Section IV) and in the political game (Section V). Section VI looks into the effect of introducing an IFC on equilibrium debt. Sections VII and VIII characterize the conditions under which setting up an IFC is in the interest of the incumbent and society, respectively. After considering alternative improvements in fiscal transparency (Section IX), we explore promising linkages between selected political indicators and the prevalence of IFCs (Section X). Section XI concludes.

\section{INDEPENDENT FISCAL COUNCILS ON THE RISE}

This section briefly discusses recent trends in the adoption of IFCs around the world, using the 2017 vintage of the IMF Fiscal Council Dataset (Debrun et al., 2017, and Beetsma et al., 2017). The IMF dataset follows Debrun et al. (2013) who define an independent fiscal council as "a permanent agency with a statutory or executive mandate to assess publicly and independently from partisan influence government's fiscal policies, plans and performance against macroeconomic objectives related to the long-term sustainability of public finances, short-medium-term macroeconomic stability, and other official objectives. In addition, a fiscal council can also: (i) contribute to the use of unbiased macroeconomic and budgetary forecasts in budget preparation, (ii) facilitate the implementation of fiscal policy rules, (iii) cost new policy initiatives, and (iv) identify sensible fiscal policy options, and possibly, formulate recommendations.".

At end-2015, close to 40 IFCs fitting this definition were in activity (Figure 1), a three-fold increase in less than 10 years. The European Union (EU) has been at the forefront of the global trend. This is due to several new provisions of EU law-regulations constituting the so-called "Two-pack" and an intergovernmental treaty on policy coordination-mandating independent, national-level oversight of official budget forecasts and compliance with fiscal rules. Although EU legal requirements remain vague on the precise nature of the 
"independent bodies" in charge of providing such oversight, many countries ended up creating new institutions qualifying as IFCs.

Figure 1. Number of Independent Fiscal Councils in the World

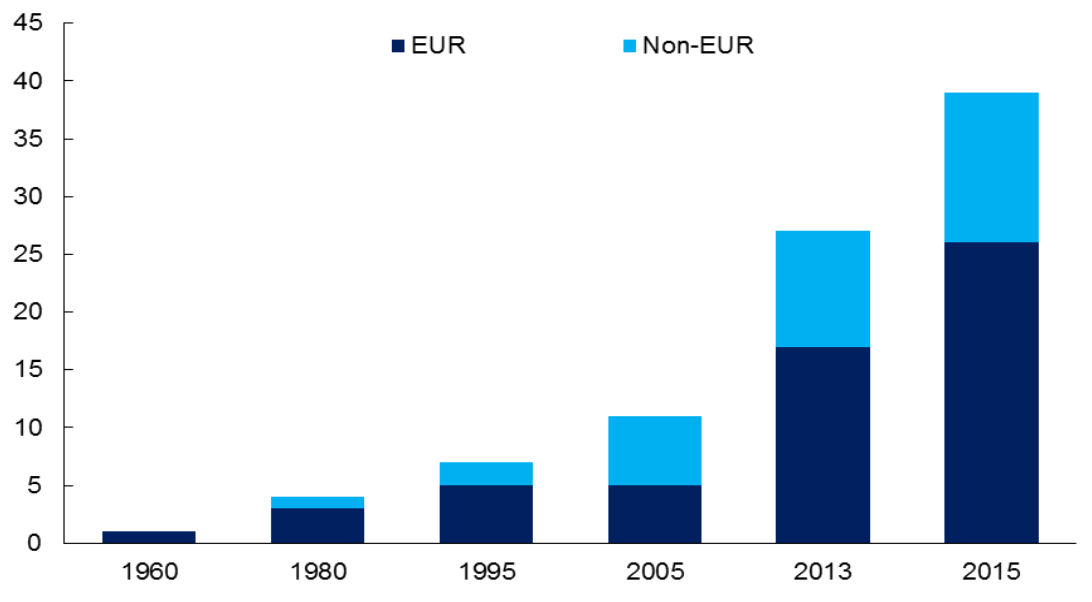

Source: Beetsma et al. (2017).

While institutional models of IFCs remain highly country-specific (see Debrun and Kinda, 2017), there is significant convergence in their remit, reflecting the aim of these institutions to better inform the public debate on fiscal policy. All IFCs are mandated to produce positive analyses of fiscal policy, and a large majority of them are also expected to assess the longterm sustainability of public finances and to prepare or at least qualitatively assess macroeconomic and budgetary forecasts (Figure 2). More than three-quarters of the councils established after 2005 monitor compliance with fiscal policy rules. This contrasts with older institutions and largely reflects the emergence of new IFCs aligned on EU requirements. Furthermore, while more than half of IFCs are expected to provide recommendations, others - such as the Office for Budget responsibility in the United Kingdom - are explicitly banned from making them. The fear is that normative statements could erode the independence of the council by placing it in the political fray. Relatively few IFCs are expected to provide costing of policy measures. 
Figure 2. The Remit of Fiscal Councils

(Relative frequencies in the sample)

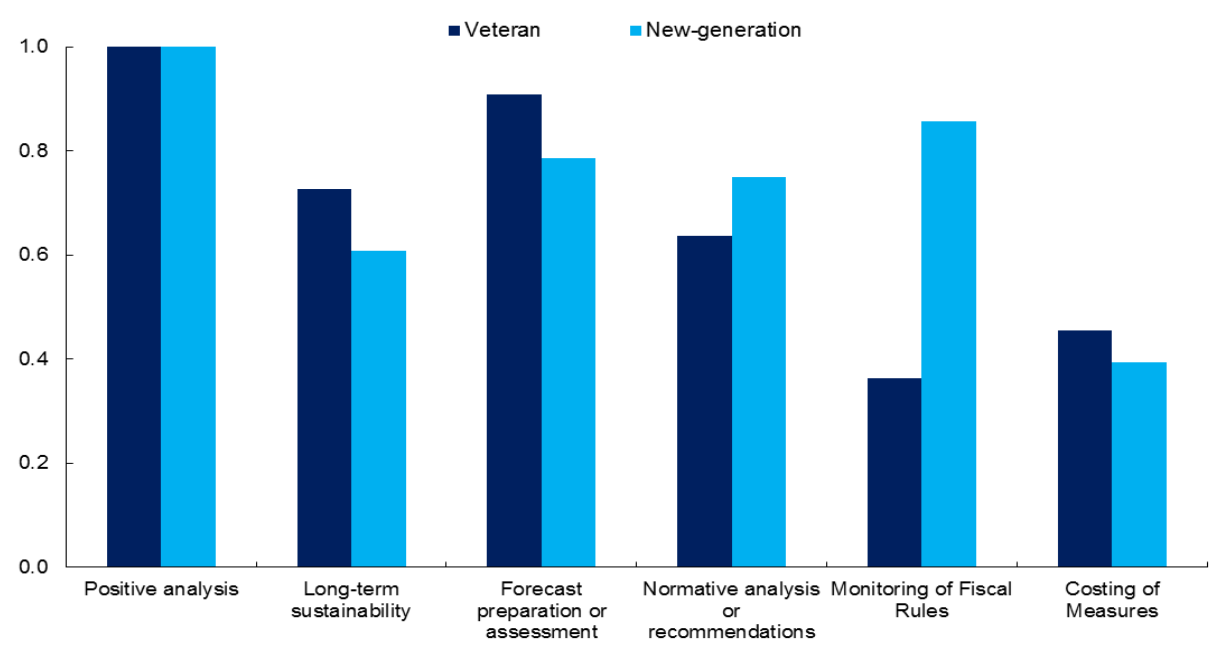

Source: Beetsma et al. (2017).

IFCs' influence on the budget process takes various forms, but is overwhelmingly indirect, through the issuance of public reports and high impact in the media (Figure 3). This again reflects their nature as institutions clarifying available signals about the quality and sustainability of fiscal policy. Slightly less than half of IFCs hold formal consultations or hearings with policymakers, which of course does not preclude informal contacts. Macroeconomic and budgetary forecasts produced by IFCs are rarely binding for budget preparation, although in about 20 percent of the cases, the government must publicly justify not using IFC forecasts and/or policy recommendations ("comply-or-explain" provision).

Figure 3. Channels of Influence on the Budget Process

(Relative frequencies in the sample)

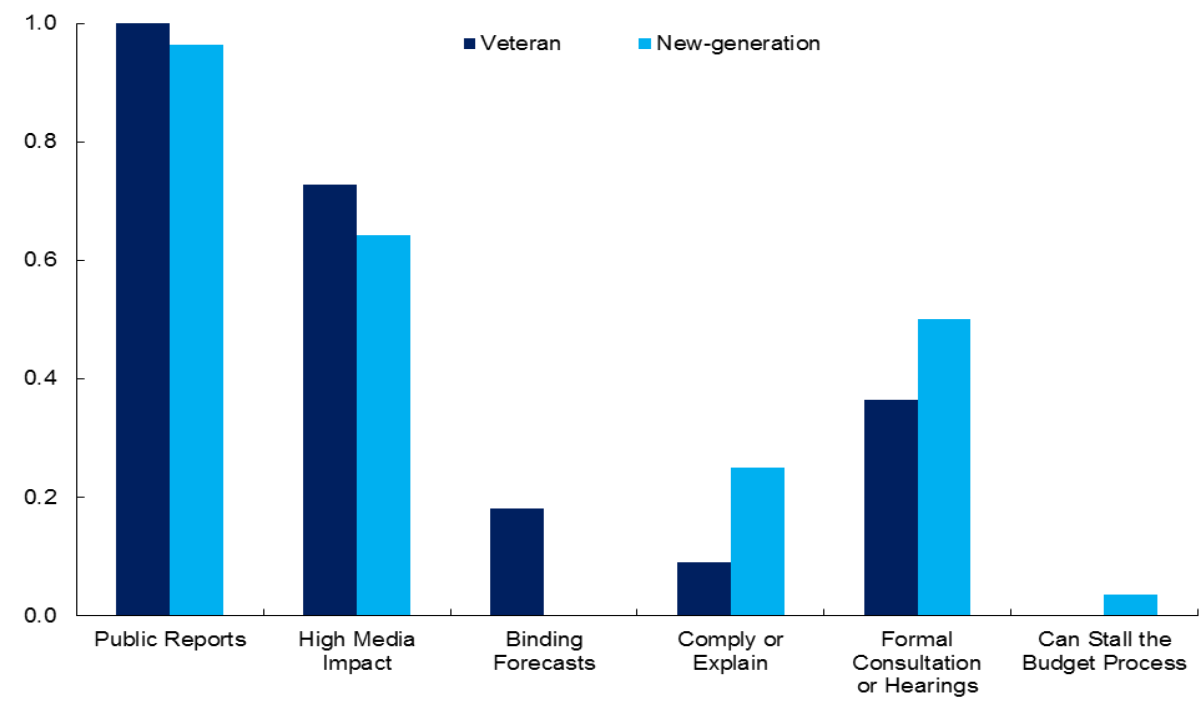

Source: Beetsma et al. (2017). 
Finally, because independence from politics is what makes IFCs a highly trusted source of unbiased information about fiscal policy, most fiscal councils benefit from specific guarantees against political interference (Figure 4). This is particularly clear among new institutions, which cannot benefit from a well-established reputation. These guarantees include formal prohibition of such interference, strict appointment/dismissal rules for management and staff, financial and human resources in line with the remit of the council, and safeguards on their budget appropriations - including a separate chapter in the overall budget, multiyear appropriations or even extra-budgetary transfers from the central bank.

Figure 4. Guarantees of Independence

(Relative frequencies in the sample)

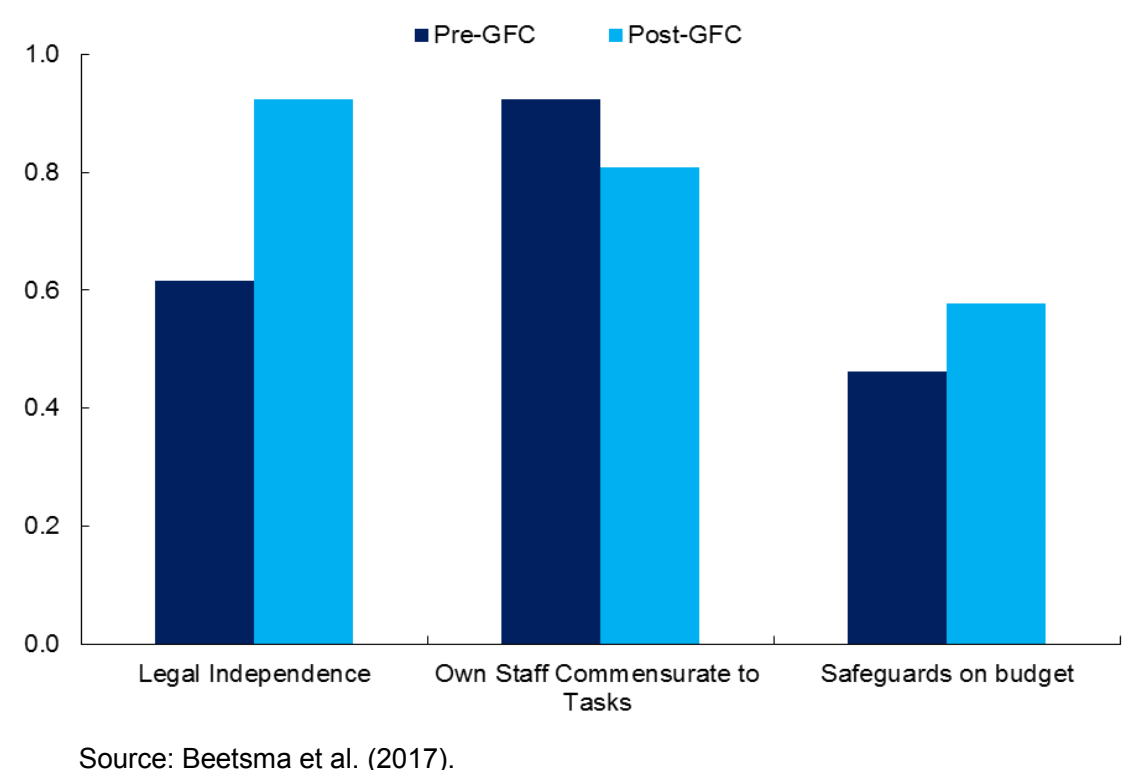

Source: Beetsma et al. (2017).

Because most IFCs were created only recently, data is too limited to allow for a comprehensive empirical analysis of their impact on fiscal performance. However, several papers have reported a positive association between the presence of a fiscal council and the quality of budgetary forecasts (e.g. Jonung and Larch, 2006; Debrun and Kinda, 2017). Evidence that IFCs contribute to more precise and less biased forecasts for budgetary aggregates would be a direct indication of their contribution to improved public information about fiscal policy. To see this, we updated an exercise performed by Debrun and Kinda (2017), using the latest vintage of the IMF Fiscal Council Dataset. For a panel of EU countries over the period 1999-2016, we regressed the absolute values of forecast errors of the primary balance on a dummy $\left(D_{-} I F C\right)$ indicating the presence of an independent fiscal council:

$A B S\left(P B_{i, t-1, t}-P B_{i, t+1, t}\right)=\alpha_{i}+\delta_{t}+\beta_{1} D_{-} I F C_{i, t-1}+\beta_{2} F R_{i, t-1}+\beta_{3} Y_{i, t-1}+\beta_{4} D_{i, t-1}+\xi_{i, t}$, 
where $i$ indexes the country and $t$ the year, $P B_{i, t-1, t}$ is the primary balance forecast in period $t$-1 for period $t, P B_{i, t+1, t}$ is the estimate in period $t+1$ for year $t, \alpha_{i}$ is a country-fixed effect, $\delta_{t}$ is a year-fixed effect, $F R_{i, t-1}$ is a fiscal rules index, which is increasing in the tightness and coverage of national fiscal rules (see Debrun et al., 2008, for details on its construction), $Y_{i, t-1}$ is the lagged output gap, $D_{i, t-1}$ is the lagged debt-to-GDP ratio, and $\xi_{i, t}$ is a mean-zero disturbance term. Primary balance forecasts and estimates are obtained from the EU's stability and convergence programs, while the macro-economic variables are from the April 2017 vintage of the IMF World Economic Outlook. Fixed-effect regressions yield a highlysignificant point estimate of -0.68 for $\beta_{1}$ with a robust standard error of 0.17 , indicating that in the presence of an IFC the absolute forecast error in the primary balance is smaller by 0.7 percentage points of GDP. Further details about the regression can be obtained from the authors.

\section{THE MODEL}

We propose a 2-period model (indexed by 1 and 2) with 2 political parties competing for office: $P$ and $Q$. Without loss of generality, we assume that $P$ holds office in period 1 and that an election takes place at the start of period 2 in which the incumbent $(P)$ can either be re-elected or voted out of office. The main decision $P$ makes is to allocate resources between the two periods by issuing debt (or accumulating assets). In each period, these resources are spent on public goods valued by $P, Q$, and the voters.

Resource constraints for public consumption $g_{t}(t=1,2)$ take the following form:

$$
\left\{\begin{array}{l}
g_{1}=\eta_{1}+\varepsilon+d \\
g_{2}=\eta_{2}-d
\end{array}\right.
$$

Here, $\eta_{t}$ reflects the "competence" of the elected policymaker. Competence can capture the efficiency with which resources can be transformed into public goods, the efficiency of the interaction between government and the civil service, the extent to which the government is not wasteful (not directing resources towards spending on public goods) or corrupt. Competence is not known in advance and it is stochastic. In the absence of any further information, the competence of each party is distributed normally with mean $\bar{\eta}>0$ and variance $\sigma_{\eta}^{2}>0$, i.e. $\eta_{P}, \eta_{Q} \sim N\left(\bar{\eta}, \sigma_{\eta}^{2}\right)$. As $P$ is in power in the first period, $\eta_{1}=\eta_{P}$. If $P$ is re-elected, we write $\eta_{2}=\eta_{P}$, whereas if $Q$ is elected, then $\eta_{2}=\eta_{Q}$.

Aside competence, period-1 resources are also affected by an independent, normally distributed shock $\varepsilon$ with mean zero and variance $\sigma_{\varepsilon}^{2}>0: \varepsilon \sim N\left(0, \sigma_{\varepsilon}^{2}\right)$. Resources can be reallocated over time by the issuance of public debt $d$ in period 1 to be repaid in period 2. (Of course, $d$ can be negative if the government decides to accumulate assets.) In a two-period 
setting with zero initial debt, $d$ equals the period-1 budget balance. For convenience, the (net) real interest rate is set to zero, and debt cannot exceed a given, positive upper bound $D$, i.e. $d \leq D$.

Utility is time-separable and quasi-linear: the felicity function of public goods consumption is concave in period 1 and linear in period 2. Allowing for concave period 2 felicity would substantially complicate the algebra, precluding analytical results and shifting attention away from the core insights we aim to bring out. In line with the "partisan" model of Alesina and Tabellini (1990), a political party obtains utility from public good provision only if it is in office. ${ }^{5}$ Moreover, we assume that in general, a party always prefers to be in office at all times irrespective of the debt level inherited from period 1. Hence, if not elected, a party receives utility $-K$, with $K>D-\bar{\eta} \cdot{ }^{6}$ As a result, the expected utility of the incumbent is given by $\mathrm{E}\left[u\left(g_{1}\right)\right]+\operatorname{Pr}(R) \cdot\left(g_{2}\right)+(1-\operatorname{Pr}(R)) \cdot(-K)$, where $u^{\prime}(x)>0$ and $u^{\prime \prime}(x)<0$ for all $x$, and $\operatorname{Pr}(R)$ is the (endogenous) probability of re-election of the incumbent. Expected utility of party $Q$ just before the election at the start of period 2 writes as follows: $(1-\operatorname{Pr}(\mathrm{R})) \cdot\left(g_{2}\right)+\operatorname{Pr}(\mathrm{R}) \cdot(-K)$.

Tractability is also served by assuming identical voters who share the same utility function as political parties. However, unlike elected policymakers, they are indifferent about which party is in office to provide public goods. Two distinct factors determine voters' preference for one or the other party. The first is the perceived competence $\eta$ attached to each party. The second factor, orthogonal to competence, is "congruence," a term that captures any considerationincluding ideology or the perceived empathy of party leadership for voters' concerns - that may give one party an advantage or a disadvantage in the electoral contest. Formally, the challenger $Q$ has an electoral advantage $\Delta$, such that voters prefer incumbent $P$ if $\eta_{P} \geq \eta_{Q}+\Delta$. So if $\Delta>0(\Delta<0)$, the challenger (incumbent) has an electoral advantage independent of its perceived competence.

Voters do not directly observe the incumbent's competence, but based on publicly available information (e.g. budget documents, press commentaries, political statements), they perceive a noisy signal $s_{1}$ about competence. We assume that

$$
s_{1}=\eta_{1}+\mu \text {, with the noise term } \mu \sim N\left(0, \sigma_{\mu}^{2}\right) .
$$

\footnotetext{
${ }^{5}$ It is easy to show that the "partisan" debt bias discussed below erodes if the incumbent values public good provision by the challenger in period 2, and that the bias disappears if the incumbent is indifferent about who provides the public good in period 2 .

${ }^{6}$ With $d \leq D$, the minimum expected utility in period 2 is $\bar{\eta}-D$. We assume that $-K$ is smaller than this minimum, which gives condition $K>D-\bar{\eta}$.
} 
The variance $\sigma_{\mu}^{2}$ plays a crucial role in our analysis. As discussed in Section II, the basic purpose of an IFC is to improve the public debate about fiscal policy, for instance by providing objective analysis of budgetary information, thereby enabling voters to more effectively reward good policies and sanction undesirable ones. In terms of our model, an IFC contributes to reduce the noise around policymakers' true competence. In that sense, it increases fiscal transparency. Thus, the decision to introduce (or not) an IFC can be assessed by looking at the impact of a decrease in $\sigma_{\mu}^{2}$. The response of the equilibrium debt level and social welfare to a change in the precision of $S_{1}$ is central to our analysis. ${ }^{7}$

The timing and the information structure are as follows. First, nature draws the competence levels of both party $P$ and party $Q$. Neither the parties nor the voters are informed of these draws so that none of the players in the political game initially know the parties' competence levels. ${ }^{8}$ Second, either society (i.e. the voters directly or through the legislative branch) or the incumbent (the executive) decides upon whether to establish an IFC or not. (We analyze both cases.) Third, period 1 starts with the incumbent selecting a debt level $d$, which voters cannot directly observe. The real-world counterpart to $d$ is indeed the net debt level, i.e. the gross public debt net of all government assets, whose existence is not often known to the public and whose valuation is sometimes uncertain, especially for non-financial assets. More generally, the non-observability of $d$ reflects the fact that voters ignore the details of the government's balance sheet, including its true net worth, providing fertile ground for creative accounting. For instance, Gandrud and Hallerberg (2016), show that Eurostat upward debt revisions are systematically larger for more indebted countries and when financial stress increases. In the remainder of the paper, $d$ always refers to the net debt. After $d$ is set, nature draws the unobserved shock $\varepsilon$. Then, voters can observe public consumption $g_{1}$ as they directly experience the benefit from public goods and services. In addition to $g_{1}$, which partly reflects competence, voters receive the second noisy signal of competence, $s_{1}$. Finally, at the start of period 2, elections take place based on voters' assessment of the incumbent's competence and the perceived degree of congruence of each party with their tastes outside the sheer quantity of public goods.

\footnotetext{
${ }^{7}$ The analysis looks at the marginal impact of a reduction in $\sigma_{\mu}^{2}$. Although the introduction of an IFC would effectively imply a discrete reduction in $\sigma_{\mu}^{2}$, we do not think of the noise surrounding competence as a choice parameter that can be precisely optimized or arbitrarily set to zero. No matter how large the resources of the fiscal council are, the effectiveness of the IFC itself is not under the control of policymakers, and the signal about the incumbent's competence is unlikely to ever become completely precise. However, it is certain that even if an infinitesimal reduction in $\sigma_{\mu}^{2}$ is not deemed desirable, then an IFC will not be desirable.

${ }^{8}$ One might ask why the incumbent can observe its congruence or electoral advantage, but not its own competence. In practice, frequent opinion polls give a fairly precise idea of a party's congruence with the electorate, while competence can at most be observed with error from the performance of the economy or from budgetary data.
} 


\section{First-Best Benchmark: The Social Planner Solution}

This section derives the first-best benchmark for public debt, which is selected by a social planner sharing voters' preferences. Instead of elections, the planner reappoints (or not) the incumbent policymaker to produce public goods and services. The planner ignores the incumbent's competence when choosing public debt, but he observes competence perfectly once debt has been set. The expected competence of a newly appointed policymaker ("the challenger") simply equals the unconditional mean of $\eta(\bar{\eta})$. The incumbent is reappointed whenever $\eta_{1} \geq \bar{\eta}+\Delta$, otherwise the challenger gets the job. Hence, the planner maximises: ${ }^{9}$

$$
\begin{aligned}
& \mathrm{E}\left[u\left(g_{1}\right)\right]+\operatorname{Pr}\left(\eta_{1} \geq \bar{\eta}+\Delta\right) \cdot\left(\mathrm{E}\left[\eta_{1} \mid \eta_{1} \geq \bar{\eta}+\Delta\right]-d\right)+\left(1-\operatorname{Pr}\left(\eta_{1} \geq \bar{\eta}+\Delta\right)\right) \cdot(\bar{\eta}-d+\Delta)= \\
& \mathrm{E}\left[u\left(\eta_{1}+\varepsilon+d\right)\right]+(\bar{\eta}-d)+\sigma_{\eta} \cdot \phi\left(\Delta / \sigma_{\eta}\right)+\Delta \cdot \Phi\left(\Delta / \sigma_{\eta}\right)
\end{aligned}
$$

where $\phi($.$) is the density of the standard-normal distribution and \Phi($.$) its cumulative$ distribution. The final two terms in the planner's objective function reflect selection effects. The first one arises from the reappointment of the incumbent. Given the planner's reappointment rule, a reappointed incumbent will be more competent on average than the challenger (for which competence results from a new random draw) so that he is expected to provide more public consumption. This reappointment effect always increases the planner's expected payoff and is the largest for $\Delta=0$, when congruence does confer any advantage or disadvantage to the challenger (i.e. when only competence matters). In that case, it is equal to $\sigma_{\eta} / \sqrt{2 \pi}$. The more congruence matters (i.e. the greater $|\Delta|$ ), the smaller the re-appointment effect. The final term in (3) reflects a different selection effect, this time related to partisan preferences. If the challenger is appointed, the planner obtains an extra benefit of $\Delta$ due to better congruence with voters' tastes. ${ }^{10}$ This effect can go either way, depending on whether $\Delta$ is positive or negative. Because the planner's selection decision is optimal, the sum of the two selection effects $\sigma_{\eta} \cdot \phi\left(\Delta / \sigma_{\eta}\right)+\Delta \cdot \Phi\left(\Delta / \sigma_{\eta}\right)$ must be positive.

With the planner's objective function as in (3), the first-best debt level $d^{F B}$ is fully characterized by the planner's first-order condition: ${ }^{11}$

$$
\mathrm{E}\left[u^{\prime}\left(\eta_{1}+\varepsilon+d^{F B}\right)\right]=1
$$

\footnotetext{
${ }^{9}$ Here we have used the fact that if $X \sim N\left(\mu, \sigma^{2}\right)$, then $E[X \mid X \geq a]=\mu+\sigma \cdot \phi\left(\frac{a-\mu}{\sigma}\right) /\left[1-\Phi\left(\frac{a-\mu}{\sigma}\right)\right]$.

${ }^{10}$ Note that congruence does not add resources for public consumption; we only assume that it is measured in the same terms as competence.

${ }^{11}$ Given that $u(\cdot)$ is concave, the second-order condition is immediately satisfied.
} 
Note that the selection effects - which only affect period-2 public consumption-have no impact on the first-best debt level due to the quasi-linear specification of our model.

As $d$ is expressed in net terms, $d^{F B}$ can be positive or negative. The planner might indeed decide to accumulate assets in period 1 to spend more in period 2. One of the main insights in what follows is to show that the equilibrium (net) debt level $d^{e}$ in the political game is greater than $d^{F B}$ (more gross debt or less assets), thus implying that future public consumption is smaller than its socially optimal level.

\section{Debt Choice in the Political Game}

In this section, we characterize the equilibrium debt level in the political game. The game is solved backwards, i.e. by first solving for the election outcome. At this stage, the way beliefs about policymakers' competence are formed (before and after signals are received) is crucial. We discuss this intuitively and assess how the process is affected by the debt level.

\section{A. Belief Formation and Updating}

Both the incumbent $P$ and the voter would prefer to know competence $\eta_{P}$. For a given reelection probability, better knowledge about its own competence allows the incumbent to better allocate resources inter-temporally. Similarly, ceteris paribus the voter prefers to elect more able candidates. However, competence is unobservable, leaving the incumbent and the voter the task to make inferences based on observed information $g_{1}$ and $s_{1}$. As discussed above, public consumption in the first period $\left(g_{1}\right)$ is affected by competence, debt accumulation and shocks (see (1)). Thus, once the government decides on debt, it can obtain a noisy estimate of $\eta_{1}=\eta_{P}$ such that $g_{1}-d=\eta_{1}+\varepsilon$. In addition, there is the independent signal $s_{1}$, whose precision is influenced by the fiscal council. The two signals can be used to obtain the incumbent's posterior expectation $\hat{\eta}_{1, I}=E\left(\eta_{1} \mid g_{1}, s_{1}\right)$. From the assumed normal distributions, it follows that (see Belot and van de Ven, 2011):

$$
\hat{\eta}_{1, I}=\frac{h_{\eta} \bar{\eta}+h_{\varepsilon}\left(g_{1}-d\right)+h_{\mu} s_{1}}{h_{\eta}+h_{\varepsilon}+h_{\mu}}=\frac{h_{\eta} \bar{\eta}+h_{\varepsilon}\left(\eta_{1}+\varepsilon_{1}\right)+h_{\mu} s_{1}}{h_{\eta}+h_{\varepsilon}+h_{\mu}}
$$

where $h_{\eta} \equiv 1 / \sigma_{\eta}^{2}, h_{\varepsilon} \equiv 1 / \sigma_{\varepsilon}^{2}$ and $h_{\mu} \equiv 1 / \sigma_{\mu}^{2}$ measure the precision of the various stochastic variables. ${ }^{12}$ Recall in passing that we have an interest in the role a fiscal council can play to increase fiscal transparency, which we equate with an increase in the signaling value of $s_{1}$.

\footnotetext{
${ }^{12}$ The posterior belief $f\left(\eta_{1} \mid g_{1}, s_{1}\right)$ of the incumbent given the information received is normally distributed with mean $\bar{\eta}$ and variance $\left(h_{\eta}+h_{\varepsilon}+h_{\mu}\right)^{-1}$.
} 
Therefore, $h_{\mu}$ is the lever through which an IFC can increase fiscal transparency. The incumbent's posterior expectation is simply a weighted average of the prior expectation and the two different noisy signals received, where the weights reflect the relative precision of the two information sources.

Ex-ante, the incumbent expects to receive information via signals $g_{1}$ and $s_{1}$, but does not know yet what these signals will be. Taking expectations over all the possible signals, we have that the posterior expectation $\hat{\eta}_{1, I}$ is also normally distributed, i.e. $\hat{\eta}_{1, I} \sim N\left(\bar{\eta}, \sigma_{h}^{2}\right)$, where

$$
\sigma_{h}^{2}=\frac{h_{\varepsilon}+h_{\mu}}{h_{\eta}+h_{\varepsilon}+h_{\mu}} \cdot \frac{1}{h_{\eta}}=\frac{h_{\varepsilon}+h_{\mu}}{h_{\eta}+h_{\varepsilon}+h_{\mu}} \cdot \sigma_{\eta}^{2}
$$

From an ex ante perspective, $\sigma_{h}^{2}$ can be interpreted as a measure of the signals' informativeness. The higher $\sigma_{h}^{2}$, the more informative $g_{1}$ and $s_{1}$ are about competence ex post. Note that $\sigma_{h}^{2} \leq \sigma_{\eta}^{2}$ and that $\sigma_{h}^{2}$ is strictly increasing in both $h_{\varepsilon}$ and $h_{\mu}$. In particular, $\sigma_{h}^{2}=0$ if $h_{\varepsilon}=h_{\mu}=0$. Intuitively, if $g_{1}$ and $s_{1}$ were so noisy that they would not contain any relevant information about $\eta_{1}$, the posterior expectation would always be equal to the prior expectation $\bar{\eta}$ regardless of signals $g_{1}$ and $s_{1}$ received. At the other extreme, if either $h_{\varepsilon} \rightarrow \infty$ or $h_{\mu} \rightarrow \infty$, then $\sigma_{h}^{2} \rightarrow \sigma_{\eta}^{2}$ and the incumbent would anticipate that ex post, i.e. after having received $g_{1}$ and $s_{1}$, he would know his competence with certainty. ${ }^{13}$ Similarly, $\sigma_{h}^{2}$ decreases with $h_{\eta}$. If there is less a priori uncertainty about the value of $\eta_{1}$, the additional information signals $g_{1}$ and $s_{1}$ can provide is necessarily less. In the limit where there is no ex ante uncertainty, i.e. if $h_{\eta} \rightarrow \infty$, we have $\sigma_{h}^{2} \rightarrow 0$. In sum, $\sigma_{h}^{2}$ reflects the incremental value of observing $g_{1}$ and $s_{1}$ from an information inference perspective.

Voters are in a less favorable position than the incumbent to make inferences about $\eta_{1}$ because they do not observe net public debt $d$. Instead, they must form beliefs $\hat{d}_{V}$ about $d$ and back these beliefs out from the government's aggregate public consumption $g_{1}$. We thus write the voter's posterior expectation:

\footnotetext{
${ }^{13}$ In that case, the posterior $\hat{\eta}_{I}$ always equals the realization $\eta_{1}$ and, hence, it must be normally distributed with mean $\bar{\eta}$ and variance $\sigma_{\eta}^{2}$.
} 


$$
\hat{\eta}_{1, V} \equiv E\left(\eta_{1} \mid g_{1}, s_{1}, \hat{d}_{V}\right)=\frac{h_{\eta} \bar{\eta}+h_{\varepsilon}\left(g_{1}-\hat{d}_{V}\right)+h_{\mu} s_{1}}{h_{\eta}+h_{\varepsilon}+h_{\mu}}=\hat{\eta}_{1, I}+\frac{h_{\varepsilon}}{h_{\eta}+h_{\varepsilon}+h_{\mu}}\left(d-\hat{d}_{V}\right)
$$

Like the incumbent's, the voter's posterior expectation is normally distributed with variance $\sigma_{h}^{2}$, but it's mean is given by the far right-hand side (r.h.s.) of (7). The latter opens up the opportunity for the incumbent to try to boost the voter's posterior expectations of its competence by choosing a higher debt level. Obviously, in equilibrium such attempts are futile, because the voters' beliefs regarding the actual debt choice are correct $\left(d=\hat{d}_{V}=d^{e}\right)$ and thus $\hat{\eta}_{1, V}=\hat{\eta}_{1, I}$.

\section{B. Election Outcome}

After the first period, the voter has an updated belief $\hat{\eta}_{1, V}$ about the expected competence of the incumbent. The expected competence of the challenger equals the prior expectation $\bar{\eta}$. Hence, if voters cared only about competence, the incumbent would be re-elected whenever $\hat{\eta}_{1, V} \geq \bar{\eta}$. If congruence also plays a role, the voter would reelect the incumbent if $\hat{\eta}_{1, V} \geq \bar{\eta}+\Delta$. The incumbent's re-election probability thus writes:

$$
p=\operatorname{Pr}\left(\hat{\eta}_{1, V} \geq \bar{\eta}+\Delta\right)=1-\Phi\left(\Gamma\left(d, \hat{d}_{V}\right)\right),
$$

where

$$
\Gamma\left(d, \hat{d}_{V}\right) \equiv \frac{1}{\sigma_{h}} \cdot\left(\Delta-\frac{h_{\varepsilon}}{h_{\eta}+h_{\varepsilon}+h_{\mu}}\left(d-\hat{d}_{V}\right)\right) .
$$

Equation (9) captures the challenger's standardized electoral advantage, i.e. the margin (in standardized units) by which the expected competence of the incumbent should exceed the expected competence of the challenger for the former to be re-elected. Notice that an increase in debt $d$ lowers $\Gamma\left(d, \hat{d}_{V}\right)$ and thus raises the re-election probability of the incumbent.

Hence, for a given debt level $\hat{d}_{V}$ expected by voters, raising debt in period 1 improves the incumbent's odds to win the elections. In equilibrium, the expected benefits from higher debt are weighed against the costs of a suboptimal inter-temporal allocation of resources. 


\section{Equilibrium Public Debt}

Turning to the next stage - the policymaker's decision about debt-the incumbent's objective can be written as: ${ }^{14}$

$$
\begin{aligned}
& \mathrm{E}\left[u\left(g_{1}\right)\right]+p \cdot\left(\mathrm{E}\left[\hat{\eta}_{1, I} \mid \hat{\eta}_{1, V} \geq \bar{\eta}+\Delta\right]-d\right)+(1-p) \cdot(-K)= \\
& \mathrm{E}\left[u\left(\eta_{1}+\varepsilon+d\right)\right]+\left[1-\Phi\left(\Gamma\left(d, \hat{d}_{V}\right)\right)\right] \cdot(K+\bar{\eta}-d)+\sigma_{h} \cdot \phi\left(\Gamma\left(d, \hat{d}_{V}\right)\right)-K
\end{aligned}
$$

Note that our assumption that $K$ is sufficiently large implies that the second term in (10) is always positive. As before, the next-to-final term in (10) reflects a selection effect. If the incumbent is re-elected, in expected terms it will be more competent than the challenger and thus better able to provide more public consumption. This term is necessarily positive as well.

The incumbent maximizes its objective (10) taking the voter's beliefs about debt $\hat{d}_{V}$ as given. The first-order condition governing his choice of debt then equals:

$$
\mathrm{E}\left[u^{\prime}\left(g_{1}\right)\right]=\left[1-\Phi\left(\Gamma\left(d, \hat{d}_{V}\right)\right)\right]-q_{h} \cdot \phi\left(\Gamma\left(d, \hat{d}_{V}\right)\right)\left(K+\bar{\eta}-d+\sigma_{h} \cdot \Gamma\left(d, \hat{d}_{V}\right)\right)
$$

where we have defined

$$
q_{h} \equiv-\frac{\partial \Gamma\left(d, \hat{d}_{V}\right)}{\partial d}=\frac{1}{\sigma_{h}} \cdot \frac{h_{\varepsilon}}{h_{\eta}+h_{\varepsilon}+h_{\mu}} .
$$

As defined in (12), $q_{h}$ reflects the extent to which an increase in debt $d$ lowers the challenger's standardized electoral advantage $\Gamma\left(d, \hat{d}_{V}\right)$, or the extent to which debt improves (in standardized units) the voter's perception of the incumbent's relative position. Note that $q_{h}=0$ when $h_{\varepsilon}=0$. Intuitively, if $g_{1}$ is so noisy that it does not convey any relevant information about $\eta_{1}$, an increase in debt (and thereby $g_{1}$ ) has no impact on the incumbent's perceived relative position. As $\sigma_{h}$ is increasing in $h_{\mu}$, it immediately follows that $q_{h}$ is decreasing in $h_{\mu}$, with $q_{h} \rightarrow 0$ for $h_{\mu} \rightarrow \infty$.

\footnotetext{
${ }^{14}$ Here we have used the general formula in footnote 9 to obtain:

$\mathrm{E}\left[\hat{\eta}_{1, I} \mid \hat{\eta}_{1, V} \geq \bar{\eta}+\Delta\right]=\mathrm{E}\left[\hat{\eta}_{1, I} \mid \hat{\eta}_{1, I} \geq \bar{\eta}+\Delta-\frac{h_{\varepsilon}}{h_{\eta}+h_{\varepsilon}+h_{\mu}}\left(d-\hat{d}_{V}\right)\right]=\bar{\eta}+\sigma_{h} \cdot \frac{\phi\left(\Gamma\left(d, \hat{d}_{V}\right)\right)}{1-\Phi\left(\Gamma\left(d, \hat{d}_{V}\right)\right)}$.
} 
In equilibrium, voter beliefs $\hat{d}_{V}$ about the selected debt level are correct: $\hat{d}_{V}=d$. In that case, the challenger's electoral advantage reduces to $\Gamma(d, d)=\Delta / \sigma_{h}$. As a result, the equilibrium debt level $d^{e}$ is characterized by:

$$
\mathrm{E}\left[u^{\prime}\left(\eta_{1}+\varepsilon+d^{e}\right)\right]=\left[1-\Phi\left(\Delta / \sigma_{h}\right)\right]-q_{h} \cdot \phi\left(\Delta / \sigma_{h}\right) \cdot\left(K+\bar{\eta}-d^{e}+\Delta\right)
$$

For (13) to fully characterize equilibrium debt, the second-order condition should also be satisfied at $\hat{d}_{V}=d=d^{e}$. A sufficient condition for this is that $\Delta$ is not too small:15

$$
\Delta>(D-\bar{\eta})-K
$$

Since we assumed that $K$ is sufficiently large, the r.h.s. in (14) is necessarily negative. In the remainder of the analysis, we assume that (14) is satisfied.

Comparing the first-order condition (13) with the social planner's (equation (4), where the r.h.s. is equal to 1) the equilibrium debt level $d^{e}$ differs from the first-best debt level $d^{F B}$, and this for two reasons. First, the incumbent only faces an inter-temporal allocation problem to the extent that he is re-elected. If he knew for sure that he would not be reelected, he would borrow as much as possible to maximize public consumption in period 1 . More generally, a fall in the re-election probability increases debt, a standard result in the "partisan bias" literature and captured by the first term on the r.h.s of (13). Second, in an (in equilibrium futile) attempt to improve electoral prospects, the incumbent chooses a higher debt to boost its competence as perceived by voters. Indeed, a higher debt allows to increase public consumption, so that the voters perceive the incumbent as more competent. This effect is captured by the second term, which is necessarily negative by assumption (14). This effect also makes higher debt more attractive to the incumbent. ${ }^{16}$

The equilibrium debt level is thus always above first best, and above the level that would have been chosen if it was not used for signal jamming purposes. Note indeed that the second term on the r.h.s. of (13) vanishes if precision $h_{\mu}$ goes to infinity and thus $q_{h}$ shrinks to zero. Intuitively, if there was perfect information on the incumbent's competence,

\footnotetext{
${ }^{15}$ See Appendix A for a formal proof that this condition is sufficient.

${ }^{16}$ The sub-term $-q_{h} \cdot \phi\left(\Delta / \sigma_{h}\right) \cdot \Delta$ within the second term reflects the impact of debt on the selection effect. This sub-term is positive when $\Delta<0$ and negative for $\Delta>0$. Intuitively, an increase in debt raises the chance to be re-elected. If $\Delta<0$, the higher re-election chance lowers the expected competence of a re-elected incumbent, because the re-election threshold on the inferred competence is relatively low. This way, the increase in debt exerts a negative effect on the incumbent's expected utility, thereby discouraging debt accumulation. The opposite is the case for $\Delta>0$.
} 
the incentive to use debt opportunistically would disappear. Only the first term on the r.h.s. would remain, leaving the partisan motive as the sole reason to choose debt above its socially optimal level. The same comparative statics result when $h_{\varepsilon}$ goes to zero. If $g_{1}$ becomes an extremely noisy signal and thus is ignored as a sign of competence, the opportunistic motive for increasing debt would also vanish.

\section{More Transparency? The Effect of a Fiscal Council on Equilibrium DEBT}

We model the introduction of a fiscal council as an increase in fiscal transparency, i.e. a reduction in the noise level surrounding the signal $s_{1}$. Formally, this raises $h_{\mu}$, with repercussions on the equilibrium level of net public debt. To see this, we differentiate the left-hand side (1.h.s.) and the r.h.s. of (13) with respect to $h_{\mu}$. Using the fact that $\partial q_{h} / \partial h_{\mu}=-\left(2 h_{\varepsilon}+q_{h} / \sigma_{h}\right)\left(\partial \sigma_{h} / \partial h_{\mu}\right)$, we obtain after some manipulations:

$$
\begin{aligned}
& \left\{\frac{\mathrm{E}\left[u^{\prime \prime}\left(\eta_{1}+\varepsilon+d^{e}\right)\right]-q_{h} \cdot \phi\left(\Delta / \sigma_{h}\right)}{\partial \sigma_{h} / \partial h_{\mu}}\right\} \cdot \frac{\partial d^{e}}{\partial h_{\mu}}=H(\Delta) \\
& \equiv \phi\left(\Delta / \sigma_{h}\right) \cdot\left[\frac{\Delta}{\sigma_{h}^{2}}\right]+\phi\left(\Delta / \sigma_{h}\right) \cdot\left\{\left(2 h_{\varepsilon}+\frac{q_{h}}{\sigma_{h}}\right)-q_{h} \cdot\left[\frac{\Delta^{2}}{\sigma_{h}^{3}}\right]\right\} \cdot\left(K+\bar{\eta}-d^{e}+\Delta\right)
\end{aligned}
$$

The fraction on the 1.h.s. is necessarily negative so that $\partial d^{e} / \partial h_{\mu}$ has the opposite sign of the r.h.s., which for ease of future reference we have defined as $H(\Delta)$.

The first term in $H(\Delta)$ captures the effect of an increase in precision on the odds of reelection. If the latter fall, a partisan policymaker turns more myopic and the partisan deficit bias increases. This happens when $\Delta<0$. In words, an increase in $h_{\mu}$ lowers the probability of re-election if congruence gives an electoral advantage to the incumbent, which means that a lower-than-average competence level can suffice to secure re-election. Intuitively, if the IFC makes $s_{1}$ more precise, assessing competence is easier, implying that the importance of the incumbent's electoral advantage in terms of congruence diminishes. The opposite happens for $\Delta>0$ (electoral disadvantage).

Interesting and clear-cut results emerge when the partisan motive is the sole reason for deficit bias. This happens when public consumption shocks are so erratic that the observed $g_{1}$ tells very little about competence. Formally, $h_{\varepsilon} \rightarrow 0$ so that $q_{h} \rightarrow 0$, suppressing the opportunistic motive to accumulate debt in period 1 (the second term in $H(\Delta)$ disappears). This result is summarized in the following proposition: 
Proposition 1. If $h_{\varepsilon} \rightarrow 0$ (suppressing the opportunistic motive to raise debt), an increase in $h_{\mu}$ raises equilibrium debt if $\Delta<0$, while it lowers equilibrium debt if $\Delta>0$. If $\Delta=0$, equilibrium debt is unaffected.

Another conjecture where the opportunistic motive for higher deficits disappears is when $S_{1}$ is not subject to noise and competence can be observed with perfect precision. In that case, the precision measure $h_{\mu}$ goes to infinity, $q_{h}$ shrinks to zero, and the final term in the firstorder condition for equilibrium debt (13) disappears. The only remaining "distortion" in debt policy is caused by the uncertainty about reelection and the related partisan bias.

To assess what happens outside this clear-cut case, we need a detailed understanding of the second term in $H(\Delta)$, which captures the overall effect of greater fiscal transparency (higher $h_{\mu}$ ) on the incentive to opportunistically raise debt. This effect is ambiguous, depending on the sign of the term in curly brackets. (Note that $K+\bar{\eta}-d^{e}+\Delta$ is positive given the assumption in (14).) To intuitively interpret the term in curly brackets, we first observe that the second cross derivative of the incumbent's re-election probability $p$ (in (8)) with respect to $d$ and $h_{\mu}$ (as evaluated at equilibrium debt) gives the following expression:

$$
\left.\frac{\partial^{2} p}{\partial d \partial h_{\mu}}\right|_{d=d^{e}}=\frac{\partial}{\partial h_{\mu}}\left[q_{h} \cdot \phi\left(\Delta / \sigma_{h}\right)\right]=-\phi\left(\Delta / \sigma_{h}\right) \cdot\left\{\left(2 h_{\varepsilon}+\frac{q_{h}}{\sigma_{h}}\right)-q_{h} \cdot\left[\frac{\Delta^{2}}{\sigma_{h}^{3}}\right]\right\} \cdot \frac{\partial \sigma_{h}}{\partial h_{\mu}}
$$

The term in curly brackets is the same as the one on the r.h.s. of (15). First, recall that $q_{h}$ reflects the extent to which an increase in debt improves the voter's perception of the incumbent's relative position. In turn, $\phi\left(\Delta / \sigma_{h}\right)$ gives the marginal increase in the incumbent's probability of re-election due to a change in such perception. Thus, the product of the two, $q_{h} \cdot \phi\left(\Delta / \sigma_{h}\right)$, is the marginal re-election probability (in equilibrium) due to an increase in debt. The question as to whether the opportunistic motive for raising debt is strengthened or weakened by an increase in transparency $h_{\mu}$ depends on how a change in $h_{\mu}$ affects $q_{h} \cdot \phi\left(\Delta / \sigma_{h}\right)$ at the margin. If $q_{h} \cdot \phi\left(\Delta / \sigma_{h}\right)$ increases with $h_{\mu}$ (i.e. higher debt has a growing positive effect on the odds of re-election), the term in curly brackets is negative, and the incumbent has stronger incentives to opportunistically raise debt in response to greater transparency. The opposite is true when $q_{h} \cdot \phi\left(\Delta / \sigma_{h}\right)$ decreases with $h_{\mu}$.

This ambiguity stems from two opposite effects. On the one hand, greater transparency $\left(h_{\mu}\right)$ erodes the influence of debt on voters' perception of the incumbent's relative position (i.e. it lowers $q_{h}$ ), weakening the opportunistic motive to raise debt. On the other hand, more 
transparency augments the signals' informativeness (i.e., it raises $\sigma_{h}^{2}$ ), which lowers $\Delta / \sigma_{h}$ and correspondingly raises the marginal effect of a change in voters' perception on reelection chances (measured by $\phi\left(\Delta / \sigma_{h}\right)$ ). This magnifies the opportunistic motive for excessive debt. Overall, as long as the role of congruence in giving electoral (dis)advantage $\Delta$ remains sufficiently limited, the first effect dominates the second, and greater transparency mitigates the opportunistic motive for excessive public debt. ${ }^{17}$ Formally, this condition writes:

$$
|\Delta| \leq \sigma_{h} \cdot \sqrt{1+\frac{2\left(h_{\varepsilon}+h_{\mu}\right)}{h_{\eta}}} \equiv \bar{\Delta}
$$

where $-\bar{\Delta}$ and $\bar{\Delta}$ are the values of $\Delta$ for which the curly term on the r.h.s. of (15) is zero, meaning that a change in transparency has no impact on the marginal re-election probability in equilibrium. If condition (16) is not satisfied, the increase in $\phi\left(\Delta / \sigma_{h}\right)$ associated with greater transparency dominates the decrease in $q_{h}$, magnifying the opportunistic motive to raise debt. From $\sigma_{h}$ increasing in $h_{\varepsilon}$ and $h_{\mu}$, and decreasing in $h_{\eta}$, it immediately follows that $\bar{\Delta}$ is also increasing in both $h_{\varepsilon}$ and $h_{\mu}$, and decreasing in $h_{\eta}$. The interval over which the introduction of an IFC mitigates the opportunistic deficit bias thus widens as $h_{\varepsilon}$ and $h_{\mu}$ increases (stronger signals of competence), and shrinks with an increase in $h_{\eta}$ (more variable competence). Proposition 2 summarizes the marginal impact of greater transparency on the opportunistic motive to increase debt in equilibrium:

Proposition 2. All else equal, and abstracting from the partisan motive to raise debt above the first best level $d^{F B}$, a marginal increase in fiscal transparency $h_{\mu}$ lowers equilibrium debt if $|\Delta|<\bar{\Delta}$, while it increases equilibrium debt if $|\Delta|>\bar{\Delta} \cdot{ }^{18}$

Propositions 1 and 2 reveal that the strength of the partisan and opportunistic motives to raise debt move in the same direction in response to greater transparency whenever $\Delta<-\bar{\Delta}$ (large electoral advantage for the incumbent) or $0<\Delta<\bar{\Delta}$ (moderate electoral disadvantage for the incumbent). In the first case, equilibrium debt increases with $h_{\mu}$, in contrast to the second case where greater transparency mitigates the debt bias. In all other conjectures, the two effects move in opposite directions and the resulting overall impact of an increase in $h_{\mu}$ on equilibrium debt depends on which effect dominates. From (15), we see that in general, for

\footnotetext{
${ }^{17}$ This follows from $\phi\left(\Delta / \sigma_{h}\right)$ being relatively flat when $\Delta$ is close to zero.

${ }^{18}$ The proposition considers the effect of small (i.e. marginal) increases in $h_{\mu}$. As $\bar{\Delta}$ increases without bounds with $h_{\mu}$, large increases in $h_{\mu}$ effectively result in cases where $|\Delta|<\bar{\Delta}$ always applies.
} 
$|\Delta| \neq \bar{\Delta}$, the opportunistic motive grows without bounds as $K$ increases, while the partisan motive is independent of $K$. Therefore, if the incumbent cares sufficiently strongly about retaining office (large $K$ ), the opportunistic motive dominates the partisan motive. ${ }^{19}$ In addition, when the opportunistic motive disappears in the limit as $h_{\varepsilon} \rightarrow 0$, the single determinant of the debt bias becomes the partisan motive. Proposition 3 combines these observations to formally characterize the joint impact of the two motives behind the debt bias.

Proposition 3. (I) The overall effect on equilibrium debt of introducing an IFC depends on the incumbent's electoral disadvantage $\Delta$. In particular, there exist two thresholds $\Delta_{L}\left(K, h_{\varepsilon}\right)$ and $\Delta_{H}\left(K, h_{\varepsilon}\right)$, with $-\bar{\Delta}<\Delta_{L}\left(K, h_{\varepsilon}\right)<0<\bar{\Delta}<\Delta_{H}\left(K, h_{\varepsilon}\right)$, such that: (I.a) if $\Delta<\Delta_{L}\left(K, h_{\varepsilon}\right)$ equilibrium debt increases with $h_{\mu}$, (I.b) if $\Delta_{L}\left(K, h_{\varepsilon}\right)<\Delta<\Delta_{H}\left(K, h_{\varepsilon}\right)$ equilibrium debt decreases with $h_{\mu}$, and (I.c) if $\Delta>\Delta_{H}\left(K, h_{\varepsilon}\right)$ equilibrium debt increases with $h_{\mu}$. (II) The threshold $\Delta_{L}\left(K, h_{\varepsilon}\right)$ is decreasing in both $K$ and $h_{\varepsilon}$, with $\lim _{K \rightarrow \infty} \Delta_{L}\left(K, h_{\varepsilon}\right)=-\bar{\Delta}$ and $\lim _{h_{\varepsilon} \rightarrow 0} \Delta_{L}\left(K, h_{\varepsilon}\right)=0$, whereas the threshold $\Delta_{H}\left(K, h_{\varepsilon}\right)$ is decreasing in $K$ and decreasing in $h_{\varepsilon}$ for $h_{\varepsilon}$ sufficiently small, with $\lim _{K \rightarrow \infty} \Delta_{H}\left(K, h_{\varepsilon}\right)=\bar{\Delta}$ and $\lim _{h_{\varepsilon} \rightarrow 0} \Delta_{H}\left(K, h_{\varepsilon}\right)=\infty$.

Proof. See Appendix A.2.

Figure 5: Debt, Transparency and Electoral Advantage

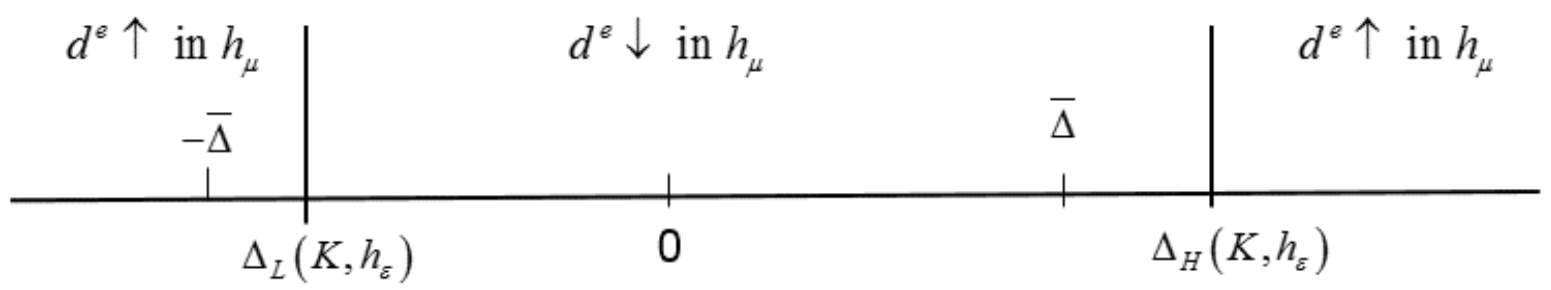

Source: Authors' illustration

The results stated under part (I) of Proposition 3 are depicted in Figure 5. First, establishing an IFC can increase equilibrium debt (i.e. worsen the debt bias compared the absence of an IFC), only if congruence overcomes competence to the point of conferring a large electoral advantage to one of the candidate. In all other cases where competence matters sufficiently, the presence of an IFC mitigates the debt bias, bringing debt closer to the first best. This is obviously true when only competence matters in the eyes of the voters. The partisan motive

${ }^{19}$ We could equivalently require $\bar{\eta}$ to be sufficiently large. 
is then unaffected (see Proposition 1), while the opportunism motive to choose higher debt levels is weakened (see Proposition 2). Intuitively, when congruence does not confer any electoral advantage, greater transparency alleviates the costly incentive for the incumbent to raise debt just to appear more competent.

\section{Who Wants a Fiscal Council? The InCUMbent's CaSe}

In equilibrium, the incumbent's utility is given by:

$$
U^{P} \equiv \mathrm{E}\left[u\left(\eta_{1}+\varepsilon+d^{e}\right)\right]+\left[1-\Phi\left(\Delta / \sigma_{h}\right)\right] \cdot\left(K+\bar{\eta}-d^{e}\right)+\sigma_{h} \cdot \phi\left(\Delta / \sigma_{h}\right)-K
$$

To assess his willingness to establish a fiscal council fostering transparency, we differentiate (17) with respect to $h_{\mu}$ and use the first-order condition for equilibrium debt (13) to obtain:

$$
\begin{aligned}
& \frac{\partial U^{P}}{\partial h_{\mu}}=-q_{h} \cdot \phi\left(\Delta / \sigma_{h}\right) \cdot\left(K+\bar{\eta}-d^{e}+\Delta\right) \cdot\left(\frac{\partial d^{e}}{\partial h_{\mu}}\right)+ \\
& \left(K+\bar{\eta}-d^{e}\right) \cdot \frac{\Delta}{\sigma_{h}^{2}} \cdot \phi\left(\Delta / \sigma_{h}\right) \cdot\left(\frac{\partial \sigma_{h}}{\partial h_{\mu}}\right)+\left(1+\frac{\Delta^{2}}{\sigma_{h}^{2}}\right) \cdot \phi\left(\Delta / \sigma_{h}\right) \cdot\left(\frac{\partial \sigma_{h}}{\partial h_{\mu}}\right)
\end{aligned}
$$

The sign of the r.h.s. (18) is ambiguous because there are political conditions in which introducing an IFC is not an attractive proposition for an incumbent government. The first term in (18) captures the effect of $h_{\mu}$ on the equilibrium path of public consumption. In the eyes of the government, greater transparency improves the intertemporal allocation of resources only if equilibrium debt falls as a result, which is not always the case (Section VI). The second term describes the effect of $h_{\mu}$ on re-election chances scaled by the unconditional average amount of resources available in period 2 (augmented by $K$ the pure utility gain from staying in office compared to being voted out). If more transparency lowers the odds of reelection, the expected benefit from being in office in period 2 falls, which reduces the marginal utility of establishing an IFC. As discussed earlier, this happens when the incumbent has an electoral advantage $(\Delta<0)$ that greater transparency (higher $\left.h_{\mu}\right)$ tends to erode. The final term characterizes the unambiguously positive selection effect associated with transparency (i.e. conditional on re-election, the incumbent will on average be more competent). 
To precisely assess the incumbent's marginal utility from greater transparency, we rearrange (18) and use (15) to substitute for $\partial d^{e} / \partial h_{\mu}$ and obtain:

$$
\frac{\partial U^{P}}{\partial h_{\mu}}=\left(\left\{\frac{\Delta}{\sigma_{h}^{2}}-q_{h} \cdot \frac{H(\Delta)}{\mathrm{E}\left[u "\left(\eta_{1}+\varepsilon+d^{e}\right)\right]-q_{h} \cdot \phi\left(\Delta / \sigma_{h}\right)}\right\} \cdot\left(K+\bar{\eta}-d^{e}+\Delta\right)+1\right) \cdot \phi\left(\Delta / \sigma_{h}\right) \cdot\left(\frac{\partial \sigma_{h}}{\partial h_{\mu}}\right)
$$

The sign of the r.h.s. of (19) crucially depends on the sign of the term in curly brackets. This term is unambiguously signed if $\Delta$ and $H(\Delta)$ have the same sign. Per Proposition 3 , this occurs when $0 \leq \Delta \leq \Delta_{H}\left(K, h_{\varepsilon}\right)$ or when $\Delta \leq \Delta_{L}\left(K, h_{\varepsilon}\right)<0$. In the first case, the r.h.s. of (19) is necessarily positive. In the second case, the r.h.s. is negative when holding office is sufficiently important for the incumbent, i.e. when $K$ is sufficiently large. Outside these special cases, the marginal effect of greater transparency on incumbent's utility is ambiguous. This leads to Proposition 4.

Proposition 4. In equilibrium, the incumbent's marginal utility of establishing an IFC depends on his electoral (dis)advantage $\Delta$. In particular, (a) if $0 \leq \Delta \leq \Delta_{H}\left(K, h_{\varepsilon}\right)$, the incumbent is better off with an IFC than without, (b) if $\Delta \leq \Delta_{L}\left(K, h_{\varepsilon}\right)$ and $K$ is sufficiently large, the incumbent is worse off with an IFC than without, and (c) in the remaining cases, the effect of an IFC on the incumbent's utility is ambiguous and generally characterized by (19). Note that absent an opportunistic motive for debt accumulation (i.e. $h_{\varepsilon} \rightarrow 0$ and thus $\left.q_{h} \rightarrow 0\right)$, and assuming that $K$ is sufficiently large, introducing an IFC makes the incumbent worse off if $\Delta<0$ and better off if $\Delta>0$.

Figure 6 illustrates the main insights from Proposition 4. First, if the incumbent has a moderate electoral disadvantage, he will welcome the introduction of a fiscal council. As discussed above, moderately low congruence implies that increased transparency makes reelection more likely (see the discussion of equation (16)), and ends up mitigating both the opportunistic and the partisan motives to raise debt. Thus, introducing an IFC lowers equilibrium debt and raises the odds of re-election, ensuring that the r.h.s. of (18) is unambiguously positive. Note that the relevant interval for $\Delta$ of course includes the special case in which voters only assess political parties based on competence (i.e. congruence does not matter: $\Delta=0) \cdot{ }^{20}$

\footnotetext{
20 This finding is reminiscent of the intuition in Holmstrom's (1999, p. 172) analysis of managerial incentives. We could paraphrase (with our changes in italics) his words as "... the incumbent cannot fool the voters. Yet he is trapped in supplying the equilibrium debt level that is expected of him, because, as in a rat race, a lower supply of $d e b t$ will bias the evaluation procedure against him." An institution which, like an IFC, can alleviate this rat race will be attractive to the participants in the rat race themselves.
} 
Figure 6. Introducing an IFC: Effect on Incumbent's Utility

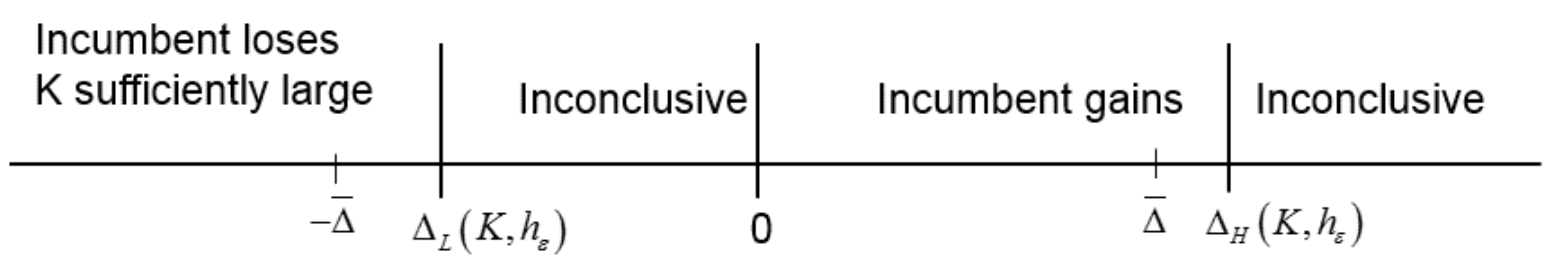

Source: Authors' illustration

In the opposite case, when the incumbent has a large political advantage, he might lose from establishing a fiscal council. If $\Delta \leq \Delta_{L}\left(K, h_{\varepsilon}\right)$, the term in the curly brackets in (19) would be negative, as more transparency raises debt and possibly also reduces re-election chances, and this could more than offset the utility gain from the selection effect. Such a situation will occur if the cost $K$ from losing office is sufficiently large because the government then has a strong incentive to reduce the likelihood of being exposed as incompetent. A similar observation applies in the absence of an opportunistic motive for debt (take $q_{h}=0$ in (19)). Then, for $\Delta<0$ (and $K$ sufficiently large) greater transparency increases the expected cost from losing office to point of exceeding the gain from the selection effect.

\section{Who Wants a Fiscal Council? The Voters' Case}

An interesting property of the model is that the incumbent's incentives to set up an IFC (and correspondingly increase transparency) are not necessarily aligned with voters'. This possible discrepancy relates to the two distinct motives for an incumbent government to accumulate debt and to the combined influence of competence and congruence on voting behavior. While the incumbent and society both dislike ex-post the opportunistic motive for debt accumulation, the partisan motive results from the incumbent's "political DNA;" it reflects a specific desire to be in office. Thus, voters and the government will agree on the desirability of an IFC to mitigate opportunistic debt buildups, but they may have conflicting views due to the impact of greater transparency on electoral outcomes. As shown above, a congruent incumbent benefitting from an electoral advantage (i.e. $\Delta<0$ ) dislikes greater transparency because it increases exposure to the risk of being deemed incompetent, and ultimately lowers reelection chances. In contrast, voters always value more precise information about competence because it improves selection at the election stage. They might nevertheless oppose the introduction of an IFC if the favorable selection effect is more than offset by higher equilibrium debt, a possibility discussed in Proposition 3. This section formally characterizes voters' preference about introducing an IFC. 
In equilibrium, social welfare is given by:

$$
\begin{aligned}
& U^{S} \equiv \mathrm{E}\left[u\left(\eta_{1}+\varepsilon+d^{e}\right)\right]+\left[1-\Phi\left(\Delta / \sigma_{h}\right)\right] \cdot\left(\mathrm{E}\left(\hat{\eta}_{1, V} \mid \hat{\eta}_{1, V} \geq \bar{\eta}+\Delta\right)-d^{e}\right)+\Phi\left(\Delta / \sigma_{h}\right) \cdot\left(\bar{\eta}-d^{e}+\Delta\right) \\
& =\mathrm{E}\left[u\left(\eta_{1}+\varepsilon+d^{e}\right)\right]+\left(\bar{\eta}-d^{e}\right)+\sigma_{h} \cdot \phi\left(\Delta / \sigma_{h}\right)+\Delta \cdot \Phi\left(\Delta / \sigma_{h}\right)
\end{aligned}
$$

Comparing (20) with (3), we see that for given equilibrium debt level the two expressions are identical, except that $\sigma_{h}$ features in (20) instead of $\sigma_{\eta}$ in (3). As established by (6), $\sigma_{h}<\sigma_{\eta}$, which implies that the sum of the last two terms of (20) is smaller than the corresponding sum in (3). ${ }^{21}$ The intuition is that the positive selection effect is necessarily larger for the social planner, because he observes $\eta_{1}$ perfectly after period 1 . In the political game, voters can only rely on noisy estimates of $g_{1}$ and $s_{1}$ instead. The more precise these estimates, the larger $\sigma_{h}$, and the larger the corresponding selection effect. At the limit, if $s_{1}$ is perfectly precise, $\sigma_{h} \rightarrow \sigma_{\eta}$ and the selection effects in (20) and in (3) are the same.

We first differentiate (20) with respect to $h_{\mu}$ and then use the first-order condition for equilibrium debt (13):

$$
\frac{\partial U^{S}}{\partial h_{\mu}}=-\left[\Phi\left(\Delta / \sigma_{h}\right)+q_{h} \cdot \phi\left(\Delta / \sigma_{h}\right) \cdot\left(K+\bar{\eta}-d^{e}+\Delta\right)\right] \cdot\left(\frac{\partial d^{e}}{\partial h_{\mu}}\right)+\phi\left(\Delta / \sigma_{h}\right) \cdot\left(\frac{\partial \sigma_{h}}{\partial h_{\mu}}\right)
$$

Compared to the corresponding expression for the incumbent (equation (18)), we immediately see that voters' views about the desirability of an IFC are only shaped by the strength of the selection effect and the impact of transparency on equilibrium debt. Reelection concerns are obviously absent, and an IFC will always be preferred if greater transparency lowers debt; there is ambiguity otherwise. Per Proposition 3, which characterizes the response of equilibrium debt to transparency, congruence and the related electoral (dis)advantage $\Delta$ play a key role in determining whether voters will support or oppose the introduction of an IFC. One limit case of interest is when the opportunistic motive vanishes, i.e. when $h_{\varepsilon} \rightarrow 0$ and thus $q_{h} \rightarrow 0$. Since only partisanship motivates a debt bias, a congruent $(\Delta<0)$ incumbent facing greater transparency will respond to diminished reelection prospects with higher debt as he discounts future public consumption more heavily. For voters, the adverse effect of higher debt will more than offset the selection effect is the concavity of first-period felicity is sufficiently weak, so that the change in equilibrium debt is large enough. ${ }^{22}$ Proposition 5 summarizes the social welfare effects of introducing an IFC:

${ }^{21}$ Differentiating the function $\sigma_{h} \cdot \phi\left(\Delta / \sigma_{h}\right)+\Delta \Phi\left(\Delta / \sigma_{h}\right)$ with respect to $\sigma_{h}$ yields $\phi\left(\Delta / \sigma_{h}\right)>0$.

${ }^{22}$ This is because for $q_{h}=0$, and by using (15), equality (21) reduces to: 
Proposition 5. In equilibrium, the marginal social welfare of establishing an IFC depends on the incumbent's electoral (dis)advantage $\Delta$. In particular, (a) if $\Delta_{L}\left(K, h_{\varepsilon}\right) \leq \Delta \leq \Delta_{H}\left(K, h_{\varepsilon}\right)$ voters are better off with an IFC than without, (b) if $\Delta<\Delta_{L}\left(K, h_{\varepsilon}\right)$ or if $\Delta>\Delta_{H}\left(K, h_{\varepsilon}\right)$, voters are worse off with an IFC than without for $K$ sufficiently large. In the absence of an opportunistic motive for debt (i.e. $q_{h}=0$ ), and assuming that the concavity of first-period felicity is sufficiently weak, voters are worse off with an IFC than without if $\Delta<0$ and better off if $\Delta>0$.

Figure 7 allows comparing propositions 4 and 5 to characterize conditions in which the incumbent and voters agree or disagree about setting up an IFC. We see that when $0 \leq \Delta \leq \Delta_{H}\left(K, h_{\varepsilon}\right)$ or $\Delta<\Delta_{L}\left(K, h_{\varepsilon}\right)$ and $K$ is sufficiently large, society and the incumbent agree on whether an IFC is attractive or not. In all other cases, they may have opposite views. First, voters may be in favor an IFC when the incumbent opposes the increased transparency that it brings about. If $K$ is sufficiently large, this can only happen when the incumbent has an electoral advantage such that $\Delta_{L}\left(K, h_{\varepsilon}\right) \leq \Delta<0$, and more specifically, when $\Delta$ is sufficiently close to $\Delta_{L}\left(K, h_{\varepsilon}\right)$ (see Appendix A.3). Hence, an incumbent with a significant but still moderate electoral advantage may decide against creating an IFC, even though voters would benefit from it.

Figure 7. Introducing an IFC: Effects on Social Welfare vs. Incumbent's Utility

\begin{tabular}{l|l|l|l}
$\begin{array}{l}\text { Both against } \\
\text { (K large enough) }\end{array}$ & $\begin{array}{l}\text { Inc. inconclusive } \\
\text { Society in favor }\end{array}$ & $\begin{array}{l}\text { Both in } \\
\text { favor }\end{array}$ & $\begin{array}{l}\text { Inc. inconcl., soc. } \\
\text { against (K large } \\
\text { enough) }\end{array}$ \\
\hline$-\bar{\Delta} \Delta_{L}\left(K, h_{\varepsilon}\right)$ & 0 & $\bar{\Delta}$ & $\Delta_{H}\left(K, h_{\varepsilon}\right)$
\end{tabular}

Source: Authors' illustration

$$
\frac{\partial U^{S}}{\partial h_{\mu}}=\left\{1-\frac{\Phi\left(\Delta / \sigma_{h}\right) \cdot \frac{\Delta}{\sigma_{h}^{2}}}{\mathrm{E}\left[u "\left(\eta_{1}+\varepsilon+d^{e}\right)\right]}\right\} \cdot \phi\left(\Delta / \sigma_{h}\right) \cdot\left(\frac{\partial \sigma_{h}}{\partial h_{\mu}}\right)
$$

Note that in the limit where $h_{\varepsilon} \rightarrow 0$ and thus $q_{h} \rightarrow 0$, both $d^{e}$ and $U^{S}$ are independent of $K$. Hence, an increase in $K$ then does not affect the misallocation of resources, and thus $U^{S}$. This is different for $U^{P}$ in (19); even in the absence of an opportunism motive an increase in $K$ lowers the incumbent's utility as losing office becomes costlier. This explains the difference in the final part of Propositions 4 and 5, respectively (i.e. $K$ is sufficiently large versus concavity of $u$ is sufficiently weak). 
Second, voters may oppose an IFC that the incumbent would be willing to create. With $K$ sufficiently large, this may occur only if $\Delta$ is above, but sufficiently close to $\Delta_{H}\left(K, h_{\varepsilon}\right)$. Hence, an incumbent with a large but not crippling electoral disadvantage may want to set up an IFC against the wishes of the electorate. The reason is that greater transparency could boost its re-election chances, even though this comes at the cost of additional opportunistic accumulation of debt. ${ }^{23}$

\section{Other Manifestations OF Fiscal Transparency}

This section expands the analysis to allow for alternative manifestations of fiscal transparency, which has so far been confined to the noise surrounding an independent signal $s_{1}$ of the incumbent's competence. In practice, fiscal transparency applies to many other aspects of budget reporting and fiscal policy making. For instance, greater transparency could mean that voters obtain independent information about the true debt level chosen by the incumbent, which in our case would mean having a clear picture of the public-sector balance sheet and the risks surrounding it. Most IFCs effectively play a role in clarifying the state of public finances and assessing the consequences of alternative policy options (or the realism of existing plans). In terms of our model, this means that instead of decreasing the noise in available signals, an IFC could increase the probability of observing the true value of uncertain variables.

To assess the robustness of our findings to other manifestations of fiscal transparency, we consider three new information channels available to voters (in addition to $g_{1}$ and $s_{1}$ ):

1. A signal on the level of public debt $s_{2}=d+\tau$, with $\tau \sim N\left(0, \sigma_{\tau}^{2}\right)$ and $h_{\tau}=1 / \sigma_{\tau}^{2}$;

2. A positive probability $\rho$ of observing the true debt $d$ (and $1-\rho$ of not observing it);

3. A positive probability $\gamma$ (independent of $\rho$ ) to observe the incumbent's true competence $\eta_{1}$ (and $1-\gamma$ of not observing it).

In addition to an increase in $h_{\mu}$, introducing an IFC could thus entail higher $h_{\tau}, \rho$, or $\gamma$. In practical terms, and in line with the remit of most of the recently-established IFCs (see Figure 2 ), the first two extensions may capture the task of many IFCs to monitor fiscal sustainability

${ }^{23}$ Comparing (20) with (17), we have: $U^{S}=U^{P}+\Phi\left(\Delta / \sigma_{h}\right) \cdot\left(K+\bar{\eta}-d^{e}+\Delta\right)$. Differentiating with respect to
signal precision, we find: $\frac{\partial U^{P}}{\partial h_{\mu}}=\frac{\partial U^{S}}{\partial h_{\mu}}+\Phi\left(\Delta / \sigma_{h}\right) \cdot\left(\frac{\partial d^{e}}{\partial h_{\mu}}\right)+\frac{\Delta}{\sigma_{h}^{2}} \cdot \phi\left(\Delta / \sigma_{h}\right) \cdot\left(K+\bar{\eta}-d^{e}+\Delta\right) \cdot\left(\frac{\partial \sigma_{h}}{\partial h_{\mu}}\right)$. This implies that, relative to voters', the incumbent's preference for creating an IFC increases if the IFC has a positive effect on equilibrium debt or if the incumbent has an electoral disadvantage. 
or compliance with fiscal rules. In the remainder of this section, we briefly comment on the comparative statics of these new parameters.

A first insight is that the additional signal $s_{2}$ on the level of public debt plays no role. Indeed, in a pure strategy equilibrium, $s_{2}$ cannot provide valuable information on the equilibrium debt and the corresponding public consumption path. Voters rely on their equilibrium belief $d=\hat{d}_{V}$, forming this belief out of $g_{1}$, rather than trying to back out a noisy $s_{2}$ out of the same observable $g_{1}$. So $s_{2}$ will be ignored simply because it is always consistent with any belief $\hat{d}_{V}$ and cannot prove such beliefs wrong. ${ }^{24}$ And off-the-equilibrium path, $s_{2}$ can play no role either because voters do not know whether they are on or off the equilibrium path in the first place. Because $s_{2}$ is ignored in equilibrium, variations in $h_{\tau}$ have no impact. Thus, if an IFC could (only) increase $h_{\tau}$, it would not affect equilibrium debt. This gives proposition 6 .

Proposition 6. An increase in $h_{\tau}$ has no impact on equilibrium debt $d^{e}, U^{P}$ and $U^{S}$.

The other two manifestations of transparency in the model do matter because certainty about $\eta_{1}$ or $d$ precludes the opportunistic use of public debt to influence voter's perceptions. In addition, observing $\eta_{1}$ directly affects the partisan motive. Indeed, knowledge of $\eta_{1}$ would give to the voter the advantage that the hypothetical social planner enjoyed in the first best (i.e. $\sigma_{h}$ would be replaced by $\sigma_{\eta}$ ). This brings the challenger's standardized electoral advantage specified in (9) closer to zero (for $d=\hat{d}_{V}$ ), which effectively reduces the incumbent's advantage if he is a priori favored (i.e. if $\Delta<0$ ).

Adding these three information channels to our original game, the first-order condition characterizing equilibrium debt becomes:

$$
\begin{aligned}
& \mathrm{E}\left[u^{\prime}\left(\eta_{1}+\varepsilon+d^{e}\right)\right]=\left[1-\Phi\left(\Delta / \sigma_{h}\right)\right]-(1-\gamma) \cdot(1-\rho) \cdot q_{h} \cdot \phi\left(\Delta / \sigma_{h}\right) \cdot\left(K+\bar{\eta}-d^{e}+\Delta\right) \\
& +\gamma \cdot\left[\Phi\left(\Delta / \sigma_{h}\right)-\Phi\left(\Delta / \sigma_{\eta}\right)\right]
\end{aligned}
$$

Expression (22) differs from (13) in two ways. First, the second term is now scaled by $(1-\gamma) \cdot(1-\rho)$, which is the probability that debt remains unobservable and can be used

\footnotetext{
${ }^{24}$ Based on Mirrlees (1999, Section 3) one might have intuitively expected that $S_{2}$ is informative, despite the infinite support of $\tau$, and thus should be considered by the voter when casting her vote. However, the crucial difference with a principal-agent setup is that there the principal can commit to a compensation schedule ex ante, while in our setup the voter cannot commit ex ante to a certain voting rule. Yet, if the voter could do so, she would commit to a voting rule that takes $S_{2}$ into account as well.
} 
opportunistically to affect the incumbent's electoral advantage (see equation (12)). Second, the final term on the r.h.s. in (22) is new and reflects the impact of possible debt observability on the partisan motive. Hence, the incumbent's equilibrium probability of re-election equals $1-\Phi\left(\Delta / \sigma_{\eta}\right)$ rather than $1-\Phi\left(\Delta / \sigma_{h}\right)$ with probability $\gamma$.

Equilibrium utility of the incumbent and equilibrium social welfare are now given by:

$$
\begin{aligned}
& U^{P} \equiv \mathrm{E}\left[u\left(\eta_{1}+\varepsilon+d^{e}\right)\right]+\left[1-\Phi\left(\Delta / \sigma_{h}\right)\right] \cdot\left(K+\bar{\eta}-d^{e}\right)+\sigma_{h} \cdot \phi\left(\Delta / \sigma_{h}\right)-K \\
& +\gamma \cdot\left[\sigma_{\eta} \cdot \phi\left(\Delta / \sigma_{\eta}\right)-\sigma_{h} \cdot \phi\left(\Delta / \sigma_{h}\right)\right]+\gamma \cdot\left[\Phi\left(\Delta / \sigma_{h}\right)-\Phi\left(\Delta / \sigma_{\eta}\right)\right] \cdot\left(K+\bar{\eta}-d^{e}\right) \\
& U^{S} \equiv \mathrm{E}\left[u\left(\eta_{1}+\varepsilon+d^{e}\right)\right]+\left(\bar{\eta}-d^{e}\right)+\sigma_{h} \cdot \phi\left(\Delta / \sigma_{h}\right)+\Delta \cdot \Phi\left(\Delta / \sigma_{h}\right) \\
& +\gamma \cdot\left[\left(\sigma_{\eta} \cdot \phi\left(\Delta / \sigma_{\eta}\right)+\Delta \cdot \Phi\left(\Delta / \sigma_{\eta}\right)\right)-\left(\sigma_{h} \cdot \phi\left(\Delta / \sigma_{h}\right)+\Delta \cdot \Phi\left(\Delta / \sigma_{h}\right)\right)\right]
\end{aligned}
$$

Comparing $U^{P}$ in (23) to the baseline expression (17), the final two terms are new. The first term is positive when $\Delta>0$ and negative when $\Delta<0$. It reflects the fact that an increase in $\gamma$ affects the incumbent's probability of re-election positively when $\Delta>0$ and negatively when $\Delta<0$. The second term reflects the improved selection (with probability $\gamma$ ) allowed by the possibility of observable competence and is necessarily positive. For $U^{S}$, a single term is added compared to the baseline specification (20). Once again, it reflects the overall positive impact of additional information on the selection effect, as a better-informed tradeoff can be made between competence and congruence. Although the improved fit in terms of expected competence comes at the expense of a worse fit in terms of partisan preferences, the overall effect is necessarily positive; otherwise the voter's election rule would be suboptimal.

Based on (22) - (24) the following propositions can be obtained (see proofs in Appendix A.4):

Proposition 7. An increase in $\rho$ necessarily lowers equilibrium debt $d^{e}$ and raises both $U^{P}$ and $U^{S}$.

Proposition 8. If $\Delta>0$, an increase in $\gamma$ necessarily lowers equilibrium debt $d^{e}$ and raises both $U^{P}$ and $U^{S}$. If $\Delta<0$, an increase in $\gamma$ has an ambiguous effect on equilibrium debt $d^{e}, U^{P}$ and $U^{S}$. In that case, for $\rho$ sufficiently close to one (i.e. when the opportunism motive vanishes), equilibrium debt is increasing in $\gamma, U^{P}$ decreases with $\gamma$ for $K$ sufficiently large, and $U^{S}$ decreases with $\gamma$ if the concavity of first-period utility is sufficiently weak. 
Proposition 7 echoes Alt and Lassen (2006), although they use a different framework. The intuition is that an increase in $\rho$ mitigates the opportunistic motive to raise debt, making the incumbent and voters better off. If an IFC could deliver perfect information about the debt level selected by the incumbent (i.e. $\rho=1$ ), the opportunistic debt bias would disappear, leaving only a partisan motive to raise debt above the first best. Proposition 1 thus immediately applies if we consider $\rho \rightarrow 1$ rather than $h_{\varepsilon} \rightarrow 0$.

Proposition 8 reveals that variations in $\gamma$ are qualitatively similar to variations in $h_{\mu}$ in the baseline model. How improved information about the incumbent's competence affects equilibrium debt and whether it is beneficial is strongly contingent on congruence as reflected in the electoral advantage $\Delta$. Here, if the incumbent is a priori disadvantaged, matters improve when $\gamma$ increases. Equilibrium debt is then lower and both the incumbent and voters benefit. This needs not be the case when the incumbent holds an electoral advantage though. As in our baseline model, the impact, viability and attractiveness of an IFC are thus closely interlinked with the relative importance of congruence as a determinant of voting behavior.

Throughout the paper, we have assumed that the government was not better informed about its own competence than the public, and that debt was not publicly observable. A plausible alternative conjecture would be one in which government has a more accurate perception of its own competence than the voter, and uses an observable debt choice to signal its competence. This turns the strategic situation into a signaling game. In an earlier paper Beetsma and Debrun (2017) study such a setting. They assume that the incumbent can be of two types only ('bad' and 'good'). Voters perfectly observe the debt level chosen by the incumbent, as well as an independent noisy signal of its competence. Mainly focusing on one specific pooling equilibrium (the one that maximizes the good type's expected utility), they show that less noise in the independent signal lowers the (pooling) equilibrium debt level. The paper, however, lacks a compelling equilibrium selection argument why this specific equilibrium should be the only one or the most plausible one to consider. The analysis in Daley and Green (2014) potentially provides such a reason. They derive conditions under which stability-based equilibrium refinements necessarily select a pooling equilibrium in settings like the one of Beetsma and Debrun (2017). Essentially, the independent noisy signal ('grade' as they call it) should be sufficiently informative relative to the cost advantage of the good type. ${ }^{25}$ Whether and how this generalizes to more than two types is not trivial.

\footnotetext{
25 An unrealistic feature of standard signaling models is that the signal is perfectly observed. Noisy signaling games in the spirit of Matthews and Mirman (1983) assume instead that the receiver only observes the sender's action with some noise. Truyts (undated) studies a setup with both noisy signaling and exogenous information ('grades') about the sender's type. His main finding is that the overall amount of information revelation can either increase or decrease if exogenous information becomes more reliable.
} 


\section{Politics And the Emergence of IFCs: Are Stylized Facts Consistent WITH THEORY?}

Our theoretical analysis has characterized broad conditions under which an elected policymaker and society both expect to benefit from setting up an IFC. A key lesson is that an IFC is not necessarily welfare improving because its existence can aggravate the bias towards excessive public debt instead of moderating it. While developing an empirical test of our theory is beyond the scope of this paper, this section briefly discusses how certain stylized facts about IFCs can be interpreted through lenses of our theory.

A first interesting observation is that most IFCs were introduced in countries where one or more fiscal rules were already in place (Beetsma and Debrun, 2017). If anything, formal restraints on debts and deficits would seem to increase the likelihood of establishing an IFC. Although we do not formally analyze the impact of fiscal policy rules and the possible complementarities with IFCs, this stylized fact would be a natural implication of our analysis. Indeed, effective fiscal rules can contain potential collateral damage of introducing an IFC (stronger debt bias), which, all else equal, should make a country with fiscal rules more likely to adopt an IFC than a country without binding restraints on deficits and debts.

A second important observation is that fiscal councils have tended to emerge in the more mature, liberal-democratic systems where democratic accountability can easily lead to changes in governing teams (Beetsma and Debrun, 2017, Figure 5.3b). This is what our theory predicts when it suggests that ceteris paribus if the incumbent's grip on power is relatively strong and the private benefit from holding office is sufficiently large, the creation of an IFC, whether initiated by society or the government, is relatively unlikely. While the private benefit from being in office is difficult to measure, we would expect it to be larger in countries with relatively high levels of corruption and illiberal regimes with an authoritarian bent. The specific case of the Netherlands illustrates this point a contrario. Dutch cabinets consist of changing coalitions anchored at the centre of the political spectrum that leave little room for populist pandering inside the cabinet. Per our theory, this political landscape provides fertile ground for an effective IFC benefitting policymakers and voters because competence would trump congruence as the main determinant of voting behavior. Hence it may not be too surprising that the Netherlands features one of the oldest and most respected IFCs in the world, the Netherlands Bureau of Economic Policy Analysis (commonly known under its Dutch acronym of CPB). ${ }^{26}$

The importance of the executive's strength for the emergence of IFCs can be further explored by looking at proxies in conventional indicators of political institutions. From the World

\footnotetext{
${ }^{26}$ A related argument is that greater democratic accountability is associated with a better capacity of governments to deliver on their promises (Gupta et al., 2017). Governments that tend to deliver on promises might thus be less fearful of establishing IFCs.
} 
Bank's Database on Political Institutions (DPI-Beck et al., 2001, and Keefer and Stasavage, 2003), we identified three proxies for executive strength. The first is the "Polariz" indicator, which captures the maximum polarization between the chief executive's party and the four main parties of the legislature. It reaches a minimum of zero when the chief executive's party has an absolute majority in the legislature. The variable "Maj" measures the margin of majority and is calculated as the number of government seats divided by the total number of seats in Parliament. Third, we look at the variable "Checks", which reflects the prevalence of checks and balances in the political system. For these three indicators, we look at whether there are significant differences between averages for country-years with an active IFC and those without an IFC. Table 1 reports the outcome of this simple exercise for a sample of the 23 original OECD members over the longest period possible (depending on DPI availability and possibly starting in 1960), and an expanded sample of 58 countries that also includes countries that joined the OECD more recently as well as non-OECD countries.

Table 1: Panel Averages of Variables Capturing Polarization Elements

\begin{tabular}{|c|c|c|c|}
\hline & Polariz & Maj & Checks \\
\hline \multicolumn{4}{|c|}{ Sample of 23 OECD countries } \\
\hline No IFC & 1.07 & 0.57 & 4.04 \\
\hline IFC & 1.71 & 0.54 & 4.77 \\
\hline Difference & $0.64^{\star \star \star}$ & $-0.033^{\star *}$ & $0.74^{\star \star \star}$ \\
\hline \multicolumn{4}{|c|}{ Sample of 58 OECD and non-OECD countries } \\
\hline No IFC & 0.71 & 0.63 & 3.49 \\
\hline IFC & 1.51 & 0.54 & 4.57 \\
\hline Difference & $0.80^{* * *}$ & $-0.088^{\star * *}$ & $1.08^{\star * *}$ \\
\hline
\end{tabular}

Notes: (i) Variables "Polariz", "Maj" and "Checks" are from the World Bank's Database on Political Institutions and carry names are identical to those used in the codebook of the dataset. For a detailed description of the variables, see the main text. (ii) We split the panel into observations (country-year) with an IFC and without an IFC, and we calculate for each subsample the average of each variable. (iii) We test significance of the difference by regressing (analogously for the other variables) Polariz $z_{i t}=$ const $+\chi D_{-} I F C_{i t}+\psi_{i t}$, where $D_{-} I F C_{i t}$ is a dummy for the presence of an IFC, const is a constant and $\psi_{i t}$ is a disturbance term. In the row "Difference", we report the estimates of $\chi$. Significance levels ("** 1 percent ${ }^{* *} 5$ percent and ${ }^{*} 10$ percent) are based on Newest-West corrected standard errors using 5 lags for the residual term.

For all three proxies of executive strength, there are statistically significant differences between countries with an IFC and those without, and these differences go in the direction predicted by our theory. First, the polarization index "Polariz" is significantly lower in the absence of an IFC, in line with our result that a stronger executive has less of an incentive to adopt an IFC that might expose it as incompetent. The same message comes out of the average margin of majority "Maj," which is significantly higher in the absence of an IFC. Finally, countries with IFCs exhibit a greater prevalence of checks and balances ("Checks"), again in line with the notion that a more constrained executive is less concerned of being harmed by the presence of an IFC. 
One last interesting stylized fact related to executive strength is that IFCs remained rare for so long and that they are occasionally subject to pressures from the executive. A large empirical literature (see, for example, Katz and King, 1999, and Jalali, 2014, Table 1) suggests that incumbents have, on average, an advantage in the electoral contest. This is because incumbents may benefit from greater name recognition, greater fundraising abilities, more press coverage, more experience in campaigning and proven experience in delivering services for their constituency. The incumbency advantage suggests that it can often be difficult to establish an IFC if the initiative is left to the government, or that an existing IFC may be abolished or fatally undermined if its legal protection is weak. It may thus help to explain why so far only a limited number of countries have established effective IFCs with a broad oversight mandate and effective safeguards on their independence, and why, in some prominent cases, the IFC was created after in the governing party or coalition.

\section{Conclusion}

This paper proposed a comprehensive theory of independent fiscal councils. The rapid increase in the number of IFCs around the globe suggests that they could be perceived as a new institutional panacea to promote sound fiscal policies. Our model addresses three related questions: How can IFCs improve the conduct of fiscal policy? Are they simultaneously desirable for voters and elected policymakers? And are they resilient to changes in political conditions? The answers are that (i) IFCs do not always lead to better fiscal outcomes, (ii) the incentives of voters and elected policymakers may not always be aligned, and (iii) IFCs can be vulnerable to political changes.

The theoretical analysis was conducted in the context of a political-economy model with uncertainty about the competence of the incumbent policymaker. The role of an IFC is to reduce that uncertainty. The model combines two sources of excessive debt: a "partisan bias" related the incumbent's myopia in the face uncertain re-election, and an "opportunistic bias" emanating from the incumbent's incentive to boost debt-financed expenditure just to appear competent. While IFCs are generally introduced with the aim to eliminate unpleasant biases in the conduct of fiscal policy, our analysis provides a more nuanced message. For instance, in the presence of a partisan bias only, an IFC reduces the incumbent's re-election chances if he enjoys an advantage in the electoral context, leading to higher debt. In the presence of the opportunistic bias only, an IFC leads to lower debt if there is no or only limited electoral advantage. However, the debt bias can become more severe if the IFC operates in a context where the incumbent enjoys a sufficiently large electoral advantage.

This ambiguity translates into potentially conflicting incentives for society (voters) and elected policymakers to establish an effective IFC. Society's willingness to do so depends on the consequences for equilibrium public debt and on its improved ability to elect policymakers on average more competent than when there is no IFC. In addition to these two factors, the incumbent also considers the effect of an IFC on re-election chances. If voters care about competence only, the introduction of an IFC benefits both the incumbent and 
society, because the opportunistic debt bias is suppressed. When congruence also matters, incumbents can benefit from an advantage or suffer from a disadvantage in the electoral contest. An incumbent with a moderate disadvantage would want to introduce an IFC, while an incumbent with a sufficiently large advantage and who greatly values being in office would prefer not to be scrutinized by an IFC.

Our analysis provides some useful lessons for the design of an effective IFC. First, the possibility that establishing an IFC could exacerbate the debt bias suggests to give the IFC a broad remit that includes analysing long-term public debt sustainability and monitoring fiscal performance against numerical fiscal rules. Recently established IFCs often include these tasks in their remit, especially those in the Euro Area. Second, our analysis highlights the inherent vulnerability of IFCs to political conditions. Strict guarantees of independence, including safeguards on financial resources, thus seem important to guarantee their sustainability over the longer run. For the same reason, adapting the IFC's institutional model to the specific characteristics of the country can increase the likelihood that its existence commands broad political consensus. To the contrary, IFCs imposed by external conditions are likely to be particularly vulnerable to political change or to be simply ignored by policymakers and the public.

The analysis in this paper suggests interesting avenues for further research. First, one may relax the assumption that, when choosing debt, the government does not have an information advantage about its own competence. Debt would then become a signalling instrument as well. Second, a fundamental question concerns the role of IFCs in relation to fiscal rules, as the latter can prevent potential collateral damage from introducing a council. We did not formally study this complementarity, but the fact that IFCs are usually established when one or more fiscal rules are already in place warrants such an analysis. 


\section{References}

Alesina, A., and G. Tabellini (1990), A positive theory of fiscal deficits and government debt, Review of Economic Studies 57, 3, 403-414.

Alt, J.E., Lassen, D.D. and S. Rose (2006), The Causes of Fiscal Transparency: Evidence from the American States, IMF Staff Papers 53, Special Issue, 30-57.

Alt, J.E., and D.D. Lassen (2006), Fiscal transparency, political parties, and debt in OECD countries, European Economic Review 50, 1403-39.

Alt, J.E., Lassen, D.D. and J. Wehner (2014), It isn't just about Greece: Domestic Politics, Transparency and Fiscal Gimmickry in Europe, British Journal of Political Science 44, 04, 707-716.

Beck, T., Clarke, G., Groff, A., Keefer, P. and P. Walsh (2001), New tools in comparative political economy: The Database of Political Institutions, World Bank Economic Review 15, 1, 165-176.

Beetsma, R., and X. Debrun (2007), The New Stability and Growth Pact: A First Assessment, European Economic Review 51, 2, 453-478.

Beetsma, R., and X. Debrun (2017), Fiscal Councils: Rationale and Effectiveness, in Ódor, L. (ed.), Rethinking Fiscal Policy after the Crisis, Cambridge University Press, Chapter $5,138-166$.

Beetsma, R., and H. Uhlig (1999), An Analysis of the Stability and Growth Pact, Economic Journal 109, 458, 546-571.

Beetsma, R., Debrun X., Fang X., Kim Y., Lledó V., Mbaye S., Yoon S., and Zhang X. (2017), The rise of independent fiscal institutions: recent trends and performance, IMF Working Paper, forthcoming.

Belot, M., and J. van de Ven (2011), Friendships and Favoritism at School - Evidence from the Field, Economic Journal 121, 1228-1251.

Bergman, U.M., and Hutchison, M. (2015), Economic Stabilisation in the Post-crisis World: Are Fiscal Rules the Answer? Journal of International Monday and Finance 52, 82101.

Bonfiglioli, A., and G. Gancia (2013), Uncertainty, Electoral Incentives and Political Myopia, Economic Journal 123, 373-400.

Calmfors, L., and S. Wren-Lewis (2011), What Should Fiscal Councils Do?, Economic Policy 26, 649-695. 
Daley, B., and B. Green, 2014, Market Signaling with Grades, Journal of Economic Theory $151,114-145$.

Debrun, X., Hauner, D. and M.S. Kumar (2013), Independent Fiscal Agencies, Journal of Economic Surveys 23, 44-81. http://www.imf.org/external/np/fad/council/

Debrun, X., and T. Kinda (2017), Strengthening Post-Crisis Fiscal Credibility-Fiscal Councils on the Rise. A New Dataset, Fiscal Studies, forthcoming. http://www.imf.org/external/np/fad/council/

Debrun, X., Kinda, T., Curristine, T., Eyraud, L. Harris, J. and J. Seiwald (2013), The Functions and Impact of Fiscal Councils, IMF Policy Paper, July 16.

Debrun, X., Moulin, L., Turrini, A., Ayuso-i-Casals, J. and M. Kumar (2008), Tied to the Mast? The Role of National Fiscal Rules in the European Union, Economic Policy 54, pp. 297-362.

Debrun, X., Zhang, X. and V. Lledo (2017), The Fiscal Council Dataset: A Primer to the 2016 Vintage, URL: http://www.imf.org/external/np/fad/council/.

Gandrud, C., and M. Hallerberg (2016), Interpreting Fiscal Accounting Rules in the European Union, Мітеo, City University of London and Hertie School of Governance.

Gavazza, A., and A. Lizzeri (2009), Transparency and Economic Policy, Review of Economic Studies 76, 1023-48.

Gavazza, A., and A. Lizzeri (2011), Transparency and Manipulation of Public Accounts, Journal of Public Economic Theory 13, 3, 327-49.

Gupta, S., Jalles, J.T., Mulas-Granados, C. and M. Schena (2017), Governments and Promised Fiscal Consolidations: Do They Mean What They Say? in Gaspar, V., Gupta, S. and C. Mulas-Granados (eds.), Fiscal Politics, Washington DC: International Monetary Fund, Chapter 2.

Horvath, M., (2016), Can Independent Fiscal Institutions Deliver Effective Oversight? Mimeo, University of York.

Holmstrom, B., (1999), Managerial Incentive Problems: A Dynamic Perspective, Review of Economic Studies 66, 1, 169-182.

Jalali, C., (2014), The 2011 Portuguese Presidential Elections: Incumbency Advantage in Semi-presidentialism? in Bosco, A. and S. Verney (eds.), Elections in Hard Times: Southern Europe 2010-11, 111-132, Routledge.

Jonung, L., and M. Larch (2006), Improving Fiscal Policy in the EU: The Case for Independent Forecasts, Economic Policy 21, 47, 492 - 534. 
Katz, J.N., and G. King (1999), A Statistical Model for Multiparty Electoral Data, American Political Science Review 93, 1, 15-32.

Keefer, P., and D. Stasavage (2003), The Limits of Delegation: Veto Players, Central Bank Independence and the Credibility of Monetary Policy, American Political Science Review 97, 3, 407-23.

Kopits, G., ed. (2013), Restoring Public Debt Sustainability: The Role of Independent Fiscal Institutions, Oxford University Press.

Larch, M., (2016), Independent Fiscal Councils: Neglected Siblings of Independent Central Banks? Mimeo, European Commission.

Leeper, E., (2011), Monetary Science, Fiscal Alchemy, in Macroeconomic Challenges: The Decade Ahead, Federal Reserve Bank of Kansas City Jackson Hole Symposium, 361434, 2011.

Madison, J., (1822), “Letter to W.T. Barry (August 4, 1822)," in G. Hunt (ed.) The Writings of James Madison, vol. 9, New York: G.P. Putnam's Sons.

Matthews, S. A., and L.J. Mirman, 1983, Equilibrium Limit Pricing: The Effects of Private Information and Stochastic Demand, Econometrica 51, 981-996.

Milesi-Ferretti, G. M., (2003), Good, Bad or Ugly? On The Effects of Fiscal Rules with Creative Accounting, Journal of Public Economics, 88, 377- 394.

Mirrlees, J.A., (1999), The Theory of Moral Hazard and Unobservable Behaviour, Part 1, Review of Economic Studies 66, 1, 3-21.

Rogoff, K., (1990), Equilibrium Political Budget Cycles, American Economic Review 80, 1, 21-36.

Rogoff, K., and A. Sibert (1988), Electoral and Macroeconomic Policy Cycles, Review of Economic Studies 55, 1, 1-16.

Truyts, T., undated, Noisy Signaling with Exogenous Information, Working Paper. 


\section{Appendix A: Additional proofs}

\section{A.1. Second-order condition}

Here we formally show that condition (14) is sufficient for the second order condition (s.o.c.) of the incumbent's maximization problem to hold. Given the f.o.c. in (11), the s.o.c. becomes:

$$
\begin{aligned}
& \mathrm{E}\left[u "\left(g_{1}\right)\right]-q_{h} \cdot \phi\left(\Gamma\left(d, \hat{d}_{V}\right)\right) \cdot\left(2+\sigma_{h} q_{h}\right) \\
& +q_{h} \cdot \Gamma\left(d, \hat{d}_{V}\right) \cdot\left\{q_{h} \cdot \phi\left(\Gamma\left(d, \hat{d}_{V}\right)\right) \cdot\left(K+\bar{\eta}-d+\sigma_{h} \cdot \Gamma\left(d, \hat{d}_{V}\right)\right)\right\}<0
\end{aligned}
$$

From $u^{\prime \prime}<0$ a sufficient condition is thus that:

$$
\Gamma\left(d, \hat{d}_{V}\right) \cdot\left\{q_{h} \cdot \phi\left(\Gamma\left(d, \hat{d}_{V}\right)\right) \cdot\left(K+\bar{\eta}-d+\sigma_{h} \cdot \Gamma\left(d, \hat{d}_{V}\right)\right)\right\}<\phi\left(\Gamma\left(d, \hat{d}_{V}\right)\right) \cdot\left(2+\sigma_{h} q_{h}\right)
$$

Using f.o.c. (11) this reduces to:

$$
\Gamma\left(d, \hat{d}_{V}\right) \cdot\left\{1-\frac{\mathrm{E}\left[u^{\prime}\left(g_{1}\right)\right]}{1-\Phi\left(\Gamma\left(d, \hat{d}_{V}\right)\right)}\right\}<\frac{\phi\left(\Gamma\left(d, \hat{d}_{V}\right)\right)}{1-\Phi\left(\Gamma\left(d, \hat{d}_{V}\right)\right)} \cdot\left(2+\sigma_{h} q_{h}\right)
$$

First suppose $\Gamma\left(d, \hat{d}_{V}\right)>0$. For the hazard rate of the standard normal distribution, it holds that $\frac{\phi(x)}{1-\Phi(x)}>x$. Therefore, as the term within curly brackets on the 1.h.s. is necessarily below 1 , the s.o.c. is always satisfied. Next, suppose $\Gamma\left(d, \hat{d}_{V}\right)<0$. A sufficient condition for the s.o.c. to hold is then that $\mathrm{E}\left[u^{\prime}\left(g_{1}\right)\right]<1-\Phi\left(\Gamma\left(d, \hat{d}_{V}\right)\right)$. From (11), this is certainly satisfied if:

$$
K+\bar{\eta}-d+\sigma_{h} \cdot \Gamma\left(d, \hat{d}_{V}\right)>0
$$

This certainly must be satisfied at $d=\hat{d}_{V}$. This reduces to $K+\bar{\eta}-d+\Delta>0$ for all $d$ and thus gives (14).

\section{A.2. Proof of Proposition 3}

From the definition of $H(\Delta)$ in (15), note that $H(\Delta)$ can be written as $H(\Delta)=\phi\left(\Delta / \sigma_{h}\right) \cdot G(\Delta)$ , with $G(\Delta)$ a cubic function of the form $c_{1} \cdot \Delta+\left(c_{2}-c_{3} \cdot \Delta^{2}\right) \cdot\left(c_{4}+\Delta\right)$, with $c_{i}>0 \forall i$ and 
with $\bar{\Delta}=\sqrt{\frac{c_{2}}{c_{3}}}$. (Obviously this form can be rewritten in the standard general form $\alpha_{0}+\alpha_{1} \cdot \Delta+\alpha_{2} \cdot \Delta^{2}+\alpha_{3} \cdot \Delta^{3}$, where $\alpha_{0}=c_{2} c_{4}>0, \alpha_{1}=c_{1}+c_{2}>0, \alpha_{2}=-c_{3} c_{4}<0$ and $\alpha_{3}=-c_{3}<0$.) From immediate inspection, it holds that $G(-\bar{\Delta})<0$ and $G(\bar{\Delta})>0$. Moreover, $G(0)>0$ as well. Hence by the intermediate value theorem, $G(\Delta)$ necessarily has a real root $G\left(\Delta_{L}\right)=0$ at some $-\bar{\Delta}<\Delta_{L}<0$. By taking first and second order derivatives, it follows that $G(\Delta)$ is strictly decreasing and strictly concave for $\Delta$ sufficiently positive, so there is another real root $G\left(\Delta_{H}\right)=0$ at some $\Delta_{H}>\bar{\Delta}$ as well. This in turn makes that there is necessarily a third root $G\left(\Delta_{L L}\right)=0$ at some very low $\Delta_{L L}<-\bar{\Delta}$. Yet for this root (14) cannot be satisfied. To see this, note first that if $-\bar{\Delta}$ does not satisfy (14), then obviously $\Delta_{L L}$ also violates it. In case $-\bar{\Delta}$ does satisfy (14), evaluate $G(\Delta)$ at $\Delta=(D-\bar{\eta})-K$. Necessarily $G(\Delta)<0$ then. But this implies that $\Delta_{L L}$ is to the left of $\Delta=(D-\bar{\eta})-K$ and hence cannot satisfy (14). Parts (I.a) - (I.c) of the proposition now follows from the fact that the sign of $\frac{\partial d^{e}}{\partial h_{\mu}}$ is opposite of the sign of $G(\Delta)$.

The values of the relevant roots $\Delta_{L}$ and $\Delta_{H}$ obviously depend on the coefficients of $G(\Delta)$, and thus (among other parameters) on $K$ and $h_{\varepsilon}$. We can thus write $\Delta_{L}\left(K, h_{\varepsilon}\right)$ and $\Delta_{H}\left(K, h_{\varepsilon}\right)$ as in the main text. First, consider how variations in $K$ affect these two relevant roots. At $\Delta=\Delta_{L}\left(K, h_{\varepsilon}\right)<0$ the first term $c_{1} \cdot \Delta$ of $G(\Delta)$ is negative and (thus) the second term $\left(c_{2}-c_{3} \cdot \Delta^{2}\right) \cdot\left(c_{4}+\Delta\right)$ is necessarily positive. Moreover, $G(\Delta)$ is strictly increasing in $\Delta$ at this root. An increase in $K$ affects (i.e. increases) coefficient $c_{4}$ only. Thus, if $K$ increases the second term becomes more positive while the first term is unaffected. Therefore, $\Delta_{L}\left(K, h_{\varepsilon}\right)$ must decrease to make the two terms cancel out again. For $\Delta=\Delta_{H}\left(K, h_{\varepsilon}\right)>0$ the reasoning is similar. The first term of $G(\Delta)$ is positive and (thus) the second term is necessarily negative. At this root, $G(\Delta)$ is decreasing. If $K$ increases the second term becomes more negative while the first term is unaffected. Therefore, $\Delta_{H}\left(K, h_{\varepsilon}\right)$ must decrease, such that the second term becomes less negative and balance is restored. The limits $\lim _{K \rightarrow \infty} \Delta_{L}\left(K, h_{\varepsilon}\right)=-\bar{\Delta}$ and $\lim _{K \rightarrow \infty} \Delta_{H}\left(K, h_{\varepsilon}\right)=\bar{\Delta}$ follow from observing that $G(\Delta)$ grows in $K$ without bounds iff $|\Delta| \neq \bar{\Delta}$. 
Finally, consider how variations in $h_{\varepsilon}$ affect $\Delta_{L}\left(K, h_{\varepsilon}\right)$ and $\Delta_{H}\left(K, h_{\varepsilon}\right)$. This is more involved than for variations in $K$, as now the three coefficients $c_{1}, c_{2}$ and $c_{3}$ are all affected by changes in $h_{\varepsilon}$. A first useful observation for characterizing the limiting behaviour of these thresholds is that $G(\Delta)$ arrives at a global maximum on the domain $\Delta>0$ for $\Delta=\Delta_{\max } \equiv-\frac{1}{3} \cdot c_{4}+\frac{1}{3} \cdot \sqrt{c_{4}^{2}+\frac{3\left(c_{1}+c_{2}\right)}{c_{3}}}$ and a global minimum on the domain $\Delta<0$ for $\Delta=\Delta_{\min } \equiv-\frac{1}{3} \cdot c_{4}-\frac{1}{3} \cdot \sqrt{c_{4}^{2}+\frac{3\left(c_{1}+c_{2}\right)}{c_{3}}}$. Now, $\frac{c_{1}}{c_{3}}=\frac{\sigma_{h}}{q_{h}}=\frac{\left(h_{\varepsilon}+h_{\mu}\right)}{h_{\varepsilon}} \cdot \frac{1}{h_{\eta}}$. This goes to infinity for $h_{\varepsilon} \rightarrow 0$. Further, one can write $\frac{c_{2}}{c_{3}}=\left[2 h_{\varepsilon} \frac{\sigma_{h}}{q_{h}}+1\right] \sigma_{h}^{2}=\left[2\left(h_{\varepsilon}+h_{\mu}\right) \frac{1}{h_{\eta}}+1\right] \frac{h_{\varepsilon}+h_{\mu}}{h_{\eta}+h_{\varepsilon}+h_{\mu}} \cdot \sigma_{\eta}^{2}$ , which converges to $\left[2 \frac{h_{\mu}}{h_{\eta}}+1\right] \frac{h_{\mu}}{h_{\eta}+h_{\mu}} \cdot \sigma_{\eta}^{2}$ as $h_{\varepsilon} \rightarrow 0$. Therefore, $\Delta_{\max }$ goes to infinity when $h_{\varepsilon} \rightarrow 0$ and, hence, also $\Delta_{H}\left(K, h_{\varepsilon}\right)$, as this threshold always exceeds $\Delta_{\max }$. Similarly so, $\Delta_{\min }$ goes to minus infinity for $h_{\varepsilon} \rightarrow 0$, and so does $\Delta_{L L}\left(K, h_{\varepsilon}\right)$. For $h_{\varepsilon}=0$ function $G(\Delta)$ becomes linear with a single root at $\Delta=0$ (note that $G(0) \rightarrow 0$ as $h_{\varepsilon} \rightarrow 0$. The single root that can converge to this one is $\Delta_{L}\left(K, h_{\varepsilon}\right)$. Therefore, $\lim _{h_{\varepsilon} \rightarrow 0} \Delta_{L}\left(K, h_{\varepsilon}\right)=0$ necessarily.

To obtain derivatives of $\Delta_{L}\left(K, h_{\varepsilon}\right)$ and $\Delta_{H}\left(K, h_{\varepsilon}\right)$ with respect to $h_{\varepsilon}$, we make the parametric dependence of $G(\Delta)$ on $h_{\varepsilon}$ explicit by writing $G\left(\Delta ; h_{\varepsilon}\right)$ and let $\Delta_{r}$ denote a root of this function. Differentiating the equality $G\left(\Delta_{r} ; h_{\varepsilon}\right)=0$ towards $h_{\varepsilon}$ and rewriting yields $\frac{\partial G}{\partial \Delta} \cdot \frac{\partial \Delta_{r}}{\partial h_{\varepsilon}}+\frac{\partial G}{\partial h_{\varepsilon}}=0 \Rightarrow \frac{\partial \Delta_{r}}{\partial h_{\varepsilon}}=-\frac{\partial G}{\partial h_{\varepsilon}} / \frac{\partial G}{\partial \Delta}$. Key is thus the sign of $\frac{\partial G}{\partial h_{\varepsilon}}$ evaluated at the root $\Delta_{r}$. (Note that from the previous analysis we already know that $\frac{\partial G}{\partial \Delta}>0$ for $\Delta_{r}=\Delta_{L}\left(K, h_{\varepsilon}\right)$ and $\frac{\partial G}{\partial \Delta}<0$ for $\Delta_{r}=\Delta_{H}\left(K, h_{\varepsilon}\right)$.) To calculate $\frac{\partial G}{\partial h_{\varepsilon}}$, rewrite $G\left(\Delta ; h_{\varepsilon}\right)$ slightly to obtain $G\left(\Delta ; h_{\varepsilon}\right)=\left[\frac{\Delta}{\sigma_{h}^{2}}\right]+\left\{2 h_{\varepsilon}+\frac{q_{h}}{\sigma_{h}} \cdot\left[1-\frac{\Delta^{2}}{\sigma_{h}^{2}}\right]\right\} \cdot\left(K+\bar{\eta}-d^{e}+\Delta\right)$. Now:
$\frac{\partial G}{\partial h_{\varepsilon}}=-2 \cdot \frac{\Delta}{\sigma_{h}^{3}} \cdot \frac{\partial \sigma_{h}}{\partial h_{\varepsilon}}+\left\{2+\left(\partial\left(\frac{q_{h}}{\sigma_{h}}\right) / \partial h_{\varepsilon}\right) \cdot\left[1-\frac{\Delta^{2}}{\sigma_{h}^{2}}\right]+\frac{q_{h}}{\sigma_{h}} \cdot 2 \cdot \frac{\Delta^{2}}{\sigma_{h}^{3}} \cdot \frac{\partial \sigma_{h}}{\partial h_{\varepsilon}}\right\} \cdot\left(K+\bar{\eta}-d^{e}+\Delta\right)$ 
From $\frac{q_{h}}{\sigma_{h}}=\frac{1}{\sigma_{h}^{2}} \cdot \frac{h_{\varepsilon}}{h_{\eta}+h_{\varepsilon}+h_{\mu}}=\frac{h_{\varepsilon} \cdot h_{\eta}}{h_{\varepsilon}+h_{\mu}}$ it follows that $\partial\left(\frac{q_{h}}{\sigma_{h}}\right) / \partial h_{\varepsilon}=\frac{h_{\mu} \cdot h_{\eta}}{\left(h_{\varepsilon}+h_{\mu}\right)^{2}}$. Moreover, at a root it holds that $\left[\frac{\Delta}{\sigma_{h}^{2}}\right]=-\left\{2 h_{\varepsilon}+\frac{q_{h}}{\sigma_{h}} \cdot\left[1-\frac{\Delta^{2}}{\sigma_{h}^{2}}\right]\right\} \cdot\left(K+\bar{\eta}-d^{e}+\Delta\right)$. We thus obtain that at a root:

$$
\begin{aligned}
& \frac{\partial G}{\partial h_{\varepsilon}}=\frac{2}{\sigma_{h}} \cdot \frac{\partial \sigma_{h}}{\partial h_{\varepsilon}} \cdot\left\{2 h_{\varepsilon}+\frac{q_{h}}{\sigma_{h}} \cdot\left[1-\frac{\Delta^{2}}{\sigma_{h}^{2}}\right]\right\} \cdot\left(K+\bar{\eta}-d^{e}+\Delta\right) \\
& +\left\{2+\frac{h_{\mu} \cdot h_{\eta}}{\left(h_{\varepsilon}+h_{\mu}\right)^{2}} \cdot\left[1-\frac{\Delta^{2}}{\sigma_{h}^{2}}\right]+\frac{q_{h}}{\sigma_{h}} \cdot 2 \cdot \frac{\Delta^{2}}{\sigma_{h}^{3}} \cdot \frac{\partial \sigma_{h}}{\partial h_{\varepsilon}}\right\} \cdot\left(K+\bar{\eta}-d^{e}+\Delta\right)
\end{aligned}
$$

Taking terms together it follows that:

$$
\operatorname{sign}\left(\frac{\partial G}{\partial h_{\varepsilon}}\right)=\operatorname{sign}\left(2+\frac{h_{\mu} \cdot h_{\eta}}{\left(h_{\varepsilon}+h_{\mu}\right)^{2}} \cdot\left[1-\frac{\Delta^{2}}{\sigma_{h}^{2}}\right]+\frac{2}{\sigma_{h}} \cdot\left(2 h_{\varepsilon}+\frac{q_{h}}{\sigma_{h}}\right) \cdot \frac{\partial \sigma_{h}}{\partial h_{\varepsilon}}\right)
$$

From $\frac{\partial \sigma_{h}^{2}}{\partial h_{\varepsilon}}=\frac{1}{\left(h_{\eta}+h_{\varepsilon}+h_{\mu}\right)^{2}}$ it follows that $\frac{\partial \sigma_{h}}{\partial h_{\varepsilon}}=\frac{1}{2 \sigma_{h}} \cdot \frac{1}{\left(h_{\eta}+h_{\varepsilon}+h_{\mu}\right)^{2}}$. Hence:

$$
\operatorname{sign}\left(\frac{\partial G}{\partial h_{\varepsilon}}\right)=\operatorname{sign}\left(2+\frac{h_{\mu} \cdot h_{\eta}}{\left(h_{\varepsilon}+h_{\mu}\right)^{2}} \cdot\left[1-\frac{\Delta^{2}}{\sigma_{h}^{2}}\right]+\left(\frac{h_{\eta}}{h_{\varepsilon}+h_{\mu}}\right)\left(2 h_{\varepsilon}+\frac{q_{h}}{\sigma_{h}}\right) \cdot\left(\frac{1}{h_{\eta}+h_{\varepsilon}+h_{\mu}}\right)\right)
$$

For $\Delta=\Delta_{L}\left(K, h_{\varepsilon}\right)<0$ the r.h.s. is necessarily positive. This follows because for $\Delta=-\bar{\Delta}$ we have $2 h_{\varepsilon}+\frac{q_{h}}{\sigma_{h}} \cdot\left[1-\frac{\Delta^{2}}{\sigma_{h}^{2}}\right]=0$ and thus $\left[1-\frac{\Delta^{2}}{\sigma_{h}^{2}}\right]=-2 h_{\varepsilon} \cdot \frac{\sigma_{h}}{q_{h}}$. Therefore, as $\frac{h_{\mu} \cdot h_{\eta}}{\left(h_{\varepsilon}+h_{\mu}\right)^{2}}=\frac{h_{\mu}}{h_{\varepsilon} \cdot\left(h_{\varepsilon}+h_{\mu}\right)} \cdot \frac{q_{h}}{\sigma_{h}}$ we obtain $\frac{h_{\mu} \cdot h_{\eta}}{\left(h_{\varepsilon}+h_{\mu}\right)^{2}} \cdot\left[1-\frac{\Delta^{2}}{\sigma_{h}^{2}}\right]=-2 \cdot \frac{h_{\mu}}{h_{\varepsilon}+h_{\mu}}$; the sum of the first two terms on the r.h.s. of (A.1) is thus already positive. Hence $\frac{\partial G}{\partial h_{\varepsilon}}>0$ at $\Delta=-\bar{\Delta}$, and thus surely also at $0>\Delta=\Delta_{L}\left(K, h_{\varepsilon}\right) \geq-\bar{\Delta}$. Therefore, $\Delta_{L}\left(K, h_{\varepsilon}\right)$ is monotonically decreasing in $h_{\varepsilon}$. 
Regarding $\Delta_{H}\left(K, h_{\varepsilon}\right)$, observe that the r.h.s. of (A.1) becomes negative for $\Delta$ large enough. Hence, when $\Delta_{H}\left(K, h_{\varepsilon}\right)$ is sufficiently large, $\Delta_{H}\left(K, h_{\varepsilon}\right)$ is decreasing in $h_{\varepsilon}$. From $\lim _{h_{\varepsilon} \rightarrow 0} \Delta_{H}\left(K, h_{\varepsilon}\right)=\infty$ it follows that this occurs for $h_{\varepsilon}$ small enough. Yet $\Delta_{H}\left(K, h_{\varepsilon}\right)$ need not monotonically decrease in $h_{\varepsilon}$. This follows, because for $\Delta$ sufficiently close to $\bar{\Delta}$, the r.h.s. of (A.1) is necessarily positive (as it is for $\Delta=-\bar{\Delta}$ from the above). Together with $\lim _{K \rightarrow \infty} \Delta_{H}\left(K, h_{\varepsilon}\right)=\bar{\Delta}$ this implies that $\Delta_{H}\left(K, h_{\varepsilon}\right)$ need not be monotonic in $h_{\varepsilon}$.

A.3. Characterization of cases where the incumbent and society disagree about attractiveness of IFC

We first show the existence of cases in which society is in favour of installing an IFC while the incumbent is against. Supposes $\Delta_{L}\left(K, h_{\varepsilon}\right) \leq \Delta<0$. Let $\Delta_{M}\left(K, h_{\varepsilon}\right)$ be the lowest value of $\Delta$ in between $\Delta_{L}\left(K, h_{\varepsilon}\right)$ and $\Delta_{H}\left(K, h_{\varepsilon}\right)$ for which the term within the curly brackets in (19) equals zero. (As this term in the curly brackets is continuous in $\Delta$, negative for $\Delta=\Delta_{L}\left(K, h_{\varepsilon}\right)$ and positive for $\Delta=\Delta_{H}\left(K, h_{\varepsilon}\right)$, by the intermediate value theorem such a root necessarily exists.) Then, for $\Delta_{L}\left(K, h_{\varepsilon}\right) \leq \Delta<\Delta_{M}\left(K, h_{\varepsilon}\right)$ and $K$ sufficiently large, $\partial U^{P} / \partial h_{\mu}<0$, as the term in the curly brackets is negative, while $\partial U^{S} / \partial h_{\mu}>0$. Next we illustrate the existence of cases in which society is against, but the incumbent is in favour of an IFC. Let $\Delta_{H H}\left(K, h_{\varepsilon}\right)$ be the lowest value of $\Delta$ above $\Delta_{H}\left(K, h_{\varepsilon}\right)$, for which the term within the curly brackets in (19) equals zero. (If no such value exists, the term in the curly brackets is positive for all $\Delta>\Delta_{H}\left(K, h_{\varepsilon}\right)$ and $\Delta_{H H}\left(K, h_{\varepsilon}\right)=\infty$.) Then for $\Delta_{H}\left(K, h_{\varepsilon}\right)<\Delta \leq \Delta_{H H}\left(K, h_{\varepsilon}\right)$ and $K$ sufficiently large $\partial U^{P} / \partial h_{\mu}>0$, as the term in the curly brackets is positive, while $\partial U^{S} / \partial h_{\mu}<0$.

\section{A.4. Proofs of Propositions 7 and 8}

For the extended model, the incumbent's objective function governing its debt choice changes from (10) to:

$$
\begin{aligned}
& \mathrm{E}\left[u\left(\eta_{1}+\varepsilon+d\right)\right]+\gamma \cdot\left\{\left[1-\Phi\left(\Delta / \sigma_{\eta}\right)\right] \cdot(K+\bar{\eta}-d)+\sigma_{\eta} \cdot \phi\left(\Delta / \sigma_{\eta}\right)\right\} \\
& +(1-\gamma) \cdot \rho \cdot\left\{\left[1-\Phi\left(\Delta / \sigma_{h}\right)\right] \cdot(K+\bar{\eta}-d)+\sigma_{h} \cdot \phi\left(\Delta / \sigma_{h}\right)\right\} \\
& +(1-\gamma) \cdot(1-\rho) \cdot\left\{\left[1-\Phi\left(\Gamma\left(d, \hat{d}_{V}\right)\right)\right] \cdot(K+\bar{\eta}-d)+\sigma_{h} \cdot \phi\left(\Gamma\left(d, \hat{d}_{V}\right)\right)\right\}-K
\end{aligned}
$$


Here, the three terms in curly brackets can be intuitively understood as follows. With probability $\gamma$ the voter learns the incumbent's competence perfectly after period one, hence there is full discriminatory power $\sigma_{\eta}$. In that case voter perceptions cannot be manipulated and the challenger's standardized handicap equals $\Delta / \sigma_{\eta}$. Similarly so, with probability $(1-\gamma) \cdot \rho$ the voter does not learn $\eta_{1}$, but observes debt perfectly. Discriminatory power of all the information received then equals $\sigma_{h}$ and the challenger's standardized handicap (which again cannot be manipulated through debt) becomes $\Delta / \sigma_{h}$. In the remaining case we are back in the original analysis with informativeness $\sigma_{h}$ and the challenger's standardized handicap equal to $\Gamma\left(d, \hat{d}_{V}\right)$, i.e. subject to manipulation. First-order condition (22) for equilibrium debt now follows immediately from differentiating (A.2) towards $d$ and an equivalent discussion as for (11) to (13) in Section $\mathrm{V}$ in the main text.

Turning to the equilibrium utilities, from (17) we know that for a given level of discriminatory power $\sigma$, expected utility of the incumbent equals:

$$
U^{P}(\sigma) \equiv \mathrm{E}\left[u\left(\eta_{1}+\varepsilon+d^{e}\right)\right]+[1-\Phi(\Delta / \sigma)] \cdot\left(K+\bar{\eta}-d^{e}\right)+\sigma \cdot \phi(\Delta / \sigma)-K
$$

The incumbent's expected utility in (23) then immediately follows from taking the weighted average $U^{P}=\gamma \cdot U^{P}\left(\sigma_{\eta}\right)+(1-\gamma) \cdot U^{P}\left(\sigma_{h}\right)=U^{P}\left(\sigma_{h}\right)+\gamma \cdot\left(U^{P}\left(\sigma_{\eta}\right)-U^{P}\left(\sigma_{h}\right)\right)$. Society's expected utility in (24) follows similarly from a corresponding weighted average based on (20).

To prove Proposition 7, differentiate (22) towards $\rho$ and rewrite to obtain:

$$
\left\{\mathrm{E}\left[u "\left(\eta_{1}+\varepsilon+d^{e}\right)\right]-(1-\gamma) \cdot(1-\rho) \cdot q_{h} \cdot \phi\left(\Delta / \sigma_{h}\right)\right\} \cdot \frac{\partial d^{e}}{\partial \rho}=(1-\gamma) \cdot q_{h} \cdot \phi\left(\Delta / \sigma_{h}\right) \cdot\left(K+\bar{\eta}-d^{e}+\Delta\right)
$$

The term within curly brackets on the 1.h.s. is necessarily negative, so the sign of $\partial d^{e} / \partial \rho$ is opposite to the sign of the r.h.s. As the latter is positive, it follows immediately that $\partial d^{e} / \partial \rho<0$ independent of $\Delta$. Now:

$$
\frac{\partial U^{P}}{\partial \rho}=\left\{\mathrm{E}\left[u^{\prime}\left(\eta_{1}+\varepsilon+d^{e}\right)\right]-\left[\left(1-\Phi\left(\Delta / \sigma_{h}\right)\right)+\gamma \cdot\left(\Phi\left(\Delta / \sigma_{h}\right)-\Phi\left(\Delta / \sigma_{\eta}\right)\right)\right]\right\} \cdot\left(\frac{\partial d^{e}}{\partial \rho}\right)
$$

The term within curly brackets is negative given first-order condition (22). Hence $\partial U^{P} / \partial \rho>0$. The result for $U^{S}$ follows similarly from noting that 
$\frac{\partial U^{S}}{\partial \rho}=\left\{\mathrm{E}\left[u^{\prime}\left(\eta_{1}+\varepsilon+d^{e}\right)\right]-1\right\} \cdot\left(\frac{\partial d^{e}}{\partial \rho}\right)$, with again the term in curly brackets negative from (22).

To prove Proposition 8 , differentiate (22) towards $\gamma$ and rewrite to obtain:

$$
\begin{aligned}
& \left\{\mathrm{E}\left[u^{\prime \prime}\left(\eta_{1}+\varepsilon+d^{e}\right)\right]-(1-\gamma) \cdot(1-\rho) \cdot q_{h} \cdot \phi\left(\Delta / \sigma_{h}\right)\right\} \cdot \frac{\partial d^{e}}{\partial \gamma} \\
& =(1-\rho) \cdot q_{h} \cdot \phi\left(\Delta / \sigma_{h}\right) \cdot\left(K+\bar{\eta}-d^{e}+\Delta\right)+\left[\Phi\left(\Delta / \sigma_{h}\right)-\Phi\left(\Delta / \sigma_{\eta}\right)\right]
\end{aligned}
$$

The term within curly brackets on the 1.h.s. is necessarily negative, so the sign of $\partial d^{e} / \partial \gamma$ is opposite to the sign of the r.h.s. The sign of term $\left[\Phi\left(\Delta / \sigma_{h}\right)-\Phi\left(\Delta / \sigma_{\eta}\right)\right]$ equals the sign of $\Delta$. Hence, when $\Delta>0$ both terms on the r.h.s. are positive and $\partial d^{e} / \partial \gamma<0$ necessarily. Otherwise, the sign of $\partial d^{e} / \partial \gamma$ can go either way. Now:

$$
\begin{aligned}
& \frac{\partial U^{P}}{\partial \gamma}=\left\{\mathrm{E}\left[u^{\prime}\left(\eta_{1}+\varepsilon+d^{e}\right)\right]-\left[\left(1-\Phi\left(\Delta / \sigma_{h}\right)\right)+\gamma \cdot\left(\Phi\left(\Delta / \sigma_{h}\right)-\Phi\left(\Delta / \sigma_{\eta}\right)\right)\right]\right\} \cdot\left(\frac{\partial d^{e}}{\partial \gamma}\right) \\
& +\left[\sigma_{\eta} \cdot \phi\left(\Delta / \sigma_{\eta}\right)-\sigma_{h} \cdot \phi\left(\Delta / \sigma_{h}\right)\right]+\left[\Phi\left(\Delta / \sigma_{h}\right)-\Phi\left(\Delta / \sigma_{\eta}\right)\right] \cdot\left(K+\bar{\eta}-d^{e}\right)
\end{aligned}
$$

The term within the curly brackets is negative given first order condition (22). The second term on the r.h.s. is necessarily positive (as $\sigma \cdot \phi(\Delta / \sigma)$ is strictly increasing in $\sigma$ ) while the sign of the final term equals the sign of $\Delta$. Hence, for $\Delta>0$ (and using $\partial d^{e} / \partial \gamma<0$ ) all r.h.s. terms are positive, while for $\Delta<0$ this need not be the case. Then, if $\rho$ is sufficiently close to one such that $\partial d^{e} / \partial \gamma$ becomes 'small' from (A.3), the negative final term will certainly outweigh for $K$ sufficiently large.

For society's equilibrium utility we obtain:

$$
\begin{aligned}
& \frac{\partial U^{S}}{\partial \gamma}=\left\{\mathrm{E}\left[u^{\prime}\left(\eta_{1}+\varepsilon+d^{e}\right)\right]-1\right\} \cdot\left(\frac{\partial d^{e}}{\partial \gamma}\right) \\
& +\left[\left(\sigma_{\eta} \cdot \phi\left(\Delta / \sigma_{\eta}\right)+\Delta \cdot \Phi\left(\Delta / \sigma_{\eta}\right)\right)-\left(\sigma_{h} \cdot \phi\left(\Delta / \sigma_{h}\right)+\Delta \cdot \Phi\left(\Delta / \sigma_{h}\right)\right)\right]
\end{aligned}
$$

The term within curly brackets is negative given first-order condition (22), while the final term is always positive (the latter follows from differentiating the function $\sigma \cdot \phi(\Delta / \sigma)+\Delta \cdot \Phi(\Delta / \sigma)$ with respect to $\sigma$, yielding $\phi(\Delta / \sigma)>0)$. Hence, for $\Delta>0$ all 
terms are positive, while for $\Delta<0$ this need not be the case. Then, if $\rho$ is sufficiently close to one such that $\partial d^{e} / \partial \gamma>0$ from (A.3), the negative first term will dominate for $\partial d^{e} / \partial \gamma$ sufficiently large, which happens from (A.3) when $\mathrm{E}\left[u "\left(\eta_{1}+\varepsilon+d^{e}\right)\right]$ is sufficiently close to zero. 